Article

\title{
The Flex-OeCoS-a Novel Optically Accessible Test Rig for the Investigation of Advanced Combustion Processes under Engine-Like Conditions
}

\author{
Bruno Schneider ${ }^{1, *(\mathbb{D})}$, Christian Schürch ${ }^{1}$, Konstantinos Boulouchos ${ }^{1}$, Stefan Herzig ${ }^{2}{ }^{\mathbb{D}}$, \\ Marc Hangartner ${ }^{2}$, David Humair ${ }^{2}$, Silas Wüthrich ${ }^{2}$, Christoph Gossweiler ${ }^{2}$ \\ and Kai Herrmann ${ }^{2}$ \\ 1 Aerothermochemistry and Combustion Systems Laboratory LAV, Institute of Energy Technology, \\ ETH Zürich, CH-8092 Zürich, Switzerland; schuercc@lav.mavt.ethz.ch (C.S.); \\ boulouchos@lav.mavt.ethz.ch (K.B.) \\ 2 Institute of Thermal and Fluid Engineering (ITFE), School of Engineering (HST), University of Applied \\ Sciences and Arts Northwestern Switzerland (FHNW), CH-5210 Windisch, Switzerland; \\ stefan-herzig@bluewin.ch (S.H.); marc.hangartner@gmx.net (M.H.); david.humair@fhnw.ch (D.H.); \\ silas.wuethrich@fhnw.ch (S.W.); christoph.gossweiler@fhnw.ch (C.G.); kai.herrmann@fhnw.ch (K.H.) \\ * Correspondence: schneider@lav.mavt.ethz.ch
}

Received: 27 February 2020; Accepted: 7 April 2020; Published: 8 April 2020

\begin{abstract}
A new test rig has been designed, built and commissioned, and is now jointly pursued to facilitate experimental investigations into advanced combustion processes (i.e., dual fuel, multi-mode) under turbulent conditions at high, engine-like temperature and pressure levels. Based on a standard diesel engine block, it offers much improved optical access to the in-cylinder processes due to its separated and rotated arrangement of the compression volume and combustion chamber, respectively. A fully variable pneumatic valve train and the appropriate preconditioning of the intake air allows it to represent a wide range of engine-like in-cylinder conditions regarding pressures, temperatures and turbulence levels. The modular design of the test rig facilitates easy optimizations of the combustion chamber/cylinder head design regarding different experimental requirements. The name of the new test rig, Flex-OeCoS, denotes its Flexibility regarding Optical engine Combustion diagnostics and/or the development of corresponding Sensing devices and applications. Measurements regarding in-cylinder gas pressures, temperatures and the flow field under typical operating conditions are presented to complete the description and assessment of the new test rig.
\end{abstract}

Keywords: Research Facilities; Experimental Apparatus; Engine Combustion; Dual Fuel; High Pressure High Temperature; Optical Access; Fine Wire Thermocouples; Pressure Indication; PIV measurements

\section{Introduction}

Over the last years, the emphasis in the development goal for new combustion engines in the field of heavy duty, power generation and marine applications has increasingly shifted from engine efficiency towards the reduction of harmful exhaust gas emissions including $\mathrm{CO}_{2}$. In this context, lean premixed or dual fuel combustion offers an inherent advantage over pure diesel type combustion since a large part of the liquid fuel can be replaced with gaseous, less carbon rich fuels. Further, due to the absence of liquid fuel and/or highly variable fuel-air ratios in the combustion zone, other harmful exhaust gas emissions are reduced as well. Thanks to new, advanced combustion concepts, the thermal efficiency of such engines can reach levels comparable to diesel engines [1]. Dual fuel combustion 
engines also offer a high degree of flexibility towards the use of different fuels, including bio-generated fuels (multi fuel) [2,3], and variations of the combustion process itself (multi-mode) [4].

Dual fuel combustion includes processes from both premixed and diffusion type combustion, the presence of a different fuel type in the premixed cylinder charge also changes the auto ignition process of the injected liquid fuel. A further development of the technology therefore necessitates a deeper understanding of many different and sometimes interlocked fundamental in-cylinder processes: liquid or gaseous fuel injection, spray breakup, evaporation and mixing, (auto)ignition and flame propagation in the evaporated fuel spray and in the premixed cylinder charge. Apart from even more detailed computer simulations, experimental investigations using (laser-)optical measurement techniques are still indispensable tools to understand those complex processes in detail.

However, on the experimental side in the portfolio of the involved research institutions (Figure 1), a test rig that could support in-depth (optical) investigations for model validation under engine relevant conditions was missing so far (as indicated by the empty box).

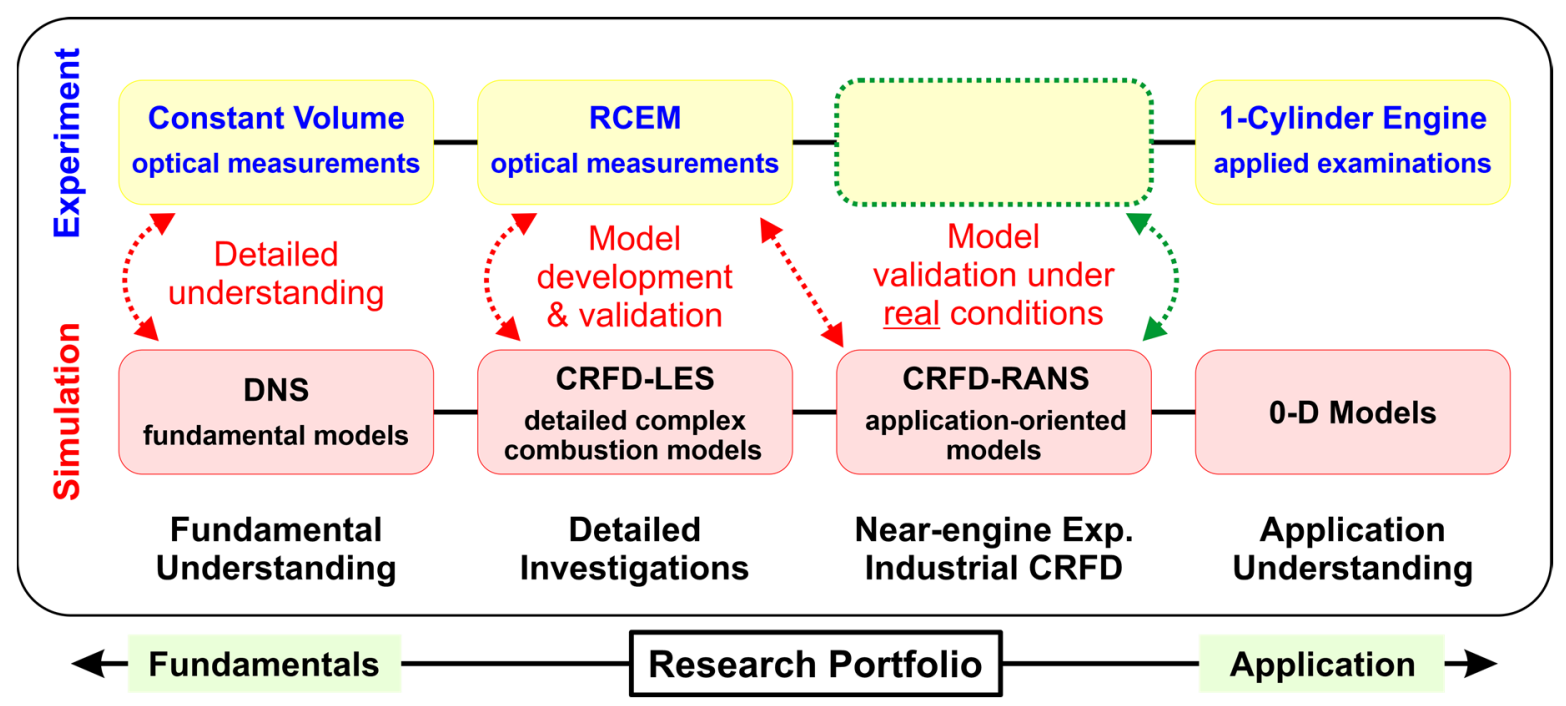

Figure 1. Research portfolio of the involved institutions related to the field of combustion engines. The empty box indicates the missing part of the experimental side.

Test rigs suitable for this type of investigations are quite challenging: Although excellent optical access to the investigated phenomena is very important, it must also be able to withstand the high pressure and temperature levels. Further, the in-cylinder flow field and turbulence level must be representative of engine conditions. A high degree of variability in its configuration, and flexibility regarding its operating conditions, are also desirable to allow for investigations into premixed, diffusion or dual/multi fuel combustion processes at the required conditions without the need for major test rig modifications.

Therefore, a new experimental facility suitable to fill this gap has been designed and built jointly in the context of a Swiss Competence Center for Energy and Mobility (CCEM-CH) project [5].

To further clarify the positioning of the new test rig, Figure 2 gives an overview of the facilities that are in use (or have been used) for experimental investigations in the context of combustion engines at the involved research institutes. Roughly, they can be divided into test rigs more suitable for fundamental investigations, where processes can be separately investigated (to some extent), and test rigs that are more representative of real, full metal multi cylinder combustion engines. 


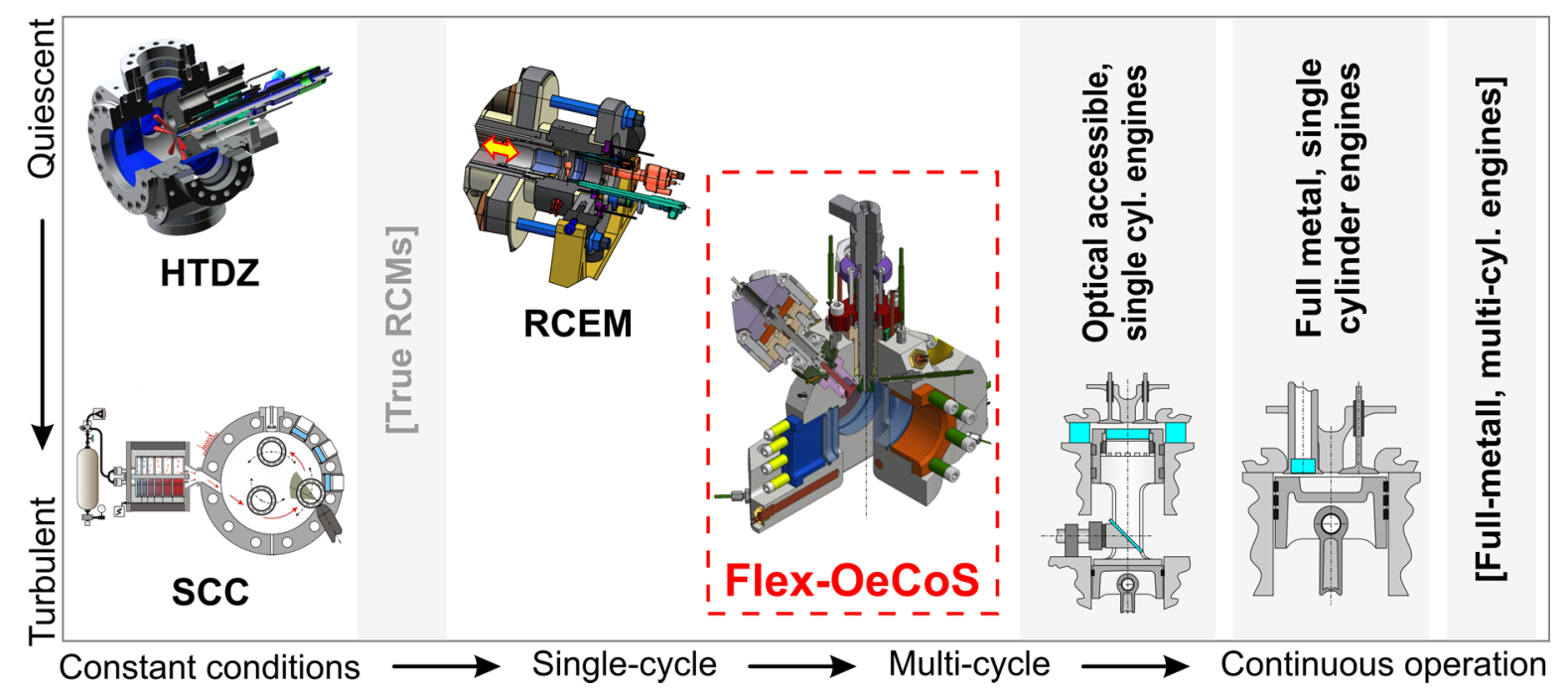

Figure 2. The new test rig (Flex-OeCoS) in the context of other, already existing test facilities at the involved research institutes. True RCMs (rapid compression machines) that lock the piston at top dead center position are not available.

Constant volume, high pressure and high temperature cells such as the HTDZ (high temperature and high pressure cell) [6-9], or the much larger SCC (spray combustion chamber) [10-13], are valuable tools to investigate fundamental processes related to diffusion combustion with liquid fuel or high-pressure gas jets [14]. Experiments with premixed or dual fuel combustion however are very difficult due to long residency time of the ignitable fuel air mixture at high temperatures (in electrically heated cells), or because the pre-combustion required to reach high gas temperatures consumes all fuel present in the cell before the actual experiment (i.e., liquid fuel injection/ignition).

On the other side of the spectrum are the (optically accessible) single cylinder engines. Full metal engines (as in [15-17]) can offer only limited (endoscopic) access into the cylinder, but impose no limits regarding cylinder pressures and temperatures and operating times (i.e., thermal load). With improving optical access, limitations regarding peak pressures, temperatures and thermal loading (number of operating cycles) play an increasingly important role [18]. Since optical engines are usually intended to operate in conditions closely approaching those of real, full metal engines, they need large gas exchange valves, which pose severe limitations for the optical access.

RCEMs (rapid compression and expansion machines) can be positioned somewhere between constant volume cells and optical single cylinder engines. They provide a single compression and expansion stroke comparable to real engines and have therefore no difficulties to work in premixed [19-21] or dual fuel combustion modes [22,23]. The filling and emptying process of the cylinder volume is decoupled from the fast compression and expansion, respectively; thus, no large intake and exhaust valves are required that limit the optical access. Usually the cylinder head is a relatively simple part that can be modified quite easily towards particular experimental needs. Due to the long filling process, however, almost no flow and turbulence is present in the cylinder at the start of compression. Options to create a flow field and turbulence at TDC (top dead center) position exist, but its effects are quite limited [24,25]. True RCMs (rapid compression machines), which do not exist in the involved research institutes, differ from RCEMs by locking the piston at the end the compression stroke. The fast compression stroke creates a high-temperature and high-pressure environment in a constant volume resulting from the locked piston. This type of machine is mostly used for fundamental studies concerning ignition and combustion processes of various fuel types. 


\section{Concept of the New Test Rig}

The new test rig is intended to fill the gap among: (1) constant volume cells (which are not suitable for premixed or dual fuel combustion); (2) rapid compression and expansion machines (which are limited in operating pressure and the achievable in-cylinder flow fields/turbulence levels); and (3) optically accessible engines (which are limited concerning operating pressures and optical access) in the context of the involved research institutes.

The major design goals are as follows:

- Excellent optical access to the combustion chamber ("see through" configuration).

- Variability: Easy exchangeable cylinder heads that are optimized for specific experimental requirements (diffusion, premixed and dual fuel/multi fuel combustion).

- Flexibility: Able to vary operating parameters (i.e., cylinder charge properties at the time of the experiment) over a wide range.

- Realize engine-like end of compression pressures/temperatures ( $>100 \mathrm{bar} / \geq 1000 \mathrm{~K}$ ) and peak combustion pressures ( $>200$ bar).

- Provide flow velocities and turbulence levels at the time of the experiment comparable to conditions found in real engines.

- No continuous operation required (single cycle experiments/limited cycle sequences only).

The following are goals not targeted by the new design:

- Processes and properties related to the late combustion phase (e.g., overall engine/combustion efficiency, or exhaust gas emissions)

Initially, the development work was focused on a hydraulically operated RCEM: since such a machine could perform an intake stroke similar to a real engine, it could also create engine-like in-cylinder flows and turbulence levels. Although the evolving design and the corresponding calculations proved the feasibility of such a concept, the necessary hydraulic piston driving system would be quite large and costly. The largest and fastest hydraulic servo-valves available on the market would have been required to control the high volume, high-pressure oil flows quickly enough. Due to the expected costs and the substantial technical risk, the initial design was therefore abandoned in favor of a concept that does not need a large hydraulic apparatus.

The new and finally realized concept is based on the simple and well-proven crankshaft/piston combination of a normal combustion engine. Since single-cycle experiments cannot be realized by quickly starting and stopping the crankshaft (which would require no less effort than the full hydraulic solution), the cylinder head is equipped with a fully variable valve train that can change the valve timing at any time. This way the actual experiment cycle can be separated from the preceding gas preparation cycle(s) and the following exhaust cycle(s).

Each gas exchange valve is an independent unit which can be positioned anywhere on the cylinder head where it does not block the optical access. This renders the test rig particularly flexible regarding the use of different cylinder head layouts, as shown in the example configurations in Figure 3 (the names for the configurations are derived from the "size class" of the observable spray length respectively cylinder/piston bowl dimensions). A change of the test rig configuration only requires the adaption of the intake and exhaust piping to the new valve locations. 


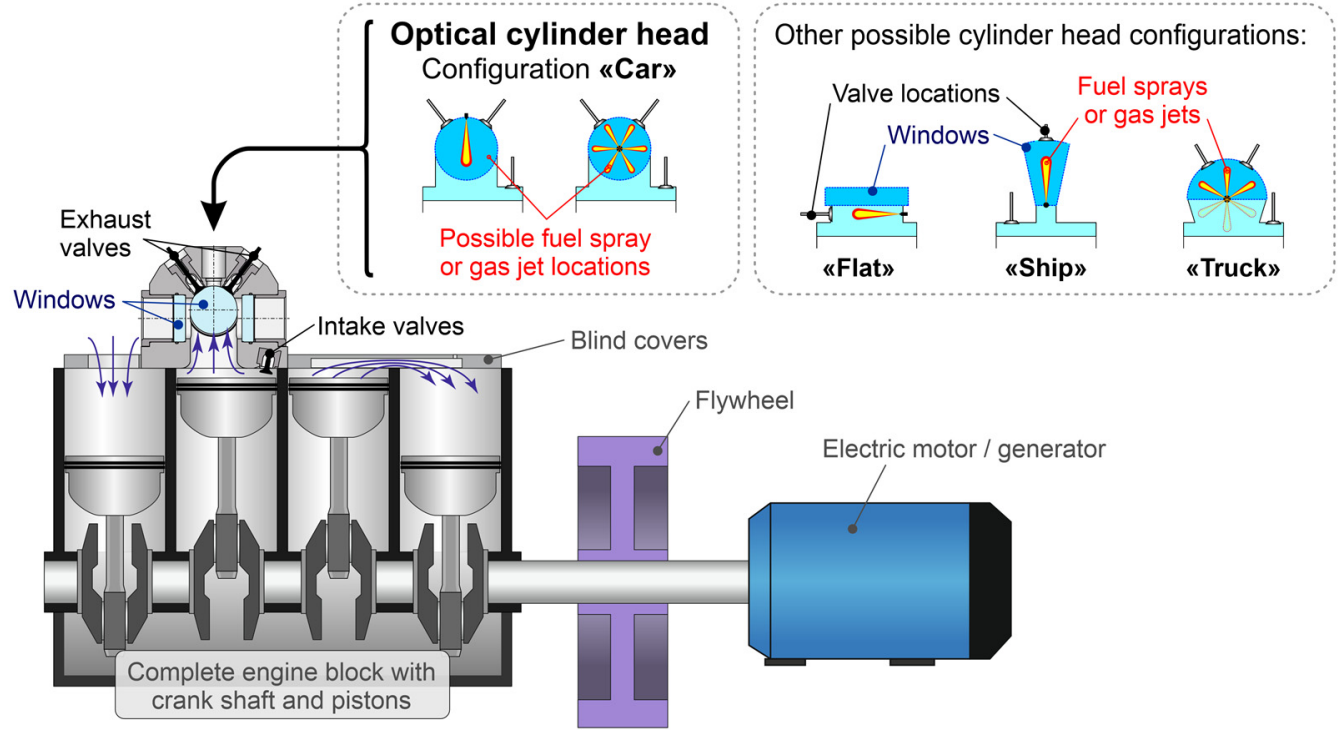

Figure 3. Sketch of the new test rig and possible optical cylinder head configurations (named according to the observable fuel spray/gas jet length "class"). The "car" type cylinder head has been realized initially.

The design selected for the initial realization is the "car" type configuration where the combustion chamber size is comparable to small car engine cylinders and piston bowl dimensions of larger diesel type car engines. The emphasis in the design of this head was primarily optical access. Therefore, the combustion chamber (i.e., the cylinder volume at TDC position) is rotated by $90^{\circ}$ and placed on top of the engine block. This way, the circular combustion chamber is almost completely optically accessible from four sides. The drawback of this approach is that there is little space available for the gas exchange valves. However, thanks to the fully variable valve train, it is possible to use multiple engine cycles to prepare or scavenge the in-cylinder gas mixture.

\section{Design of the Flex-OeCoS}

The basis of the new test rig shown in Figure 4 is a four-cylinder engine block with eight-liter displacement (D944, donated by Liebherr SA, Bulle, Switzerland). Only one cylinder is used, and the other cylinders are open to the environment (all pistons are installed to preserve mass balancing). The engine is driven by an electric motor; a large flywheel in the connecting shaft reduces speed oscillations.

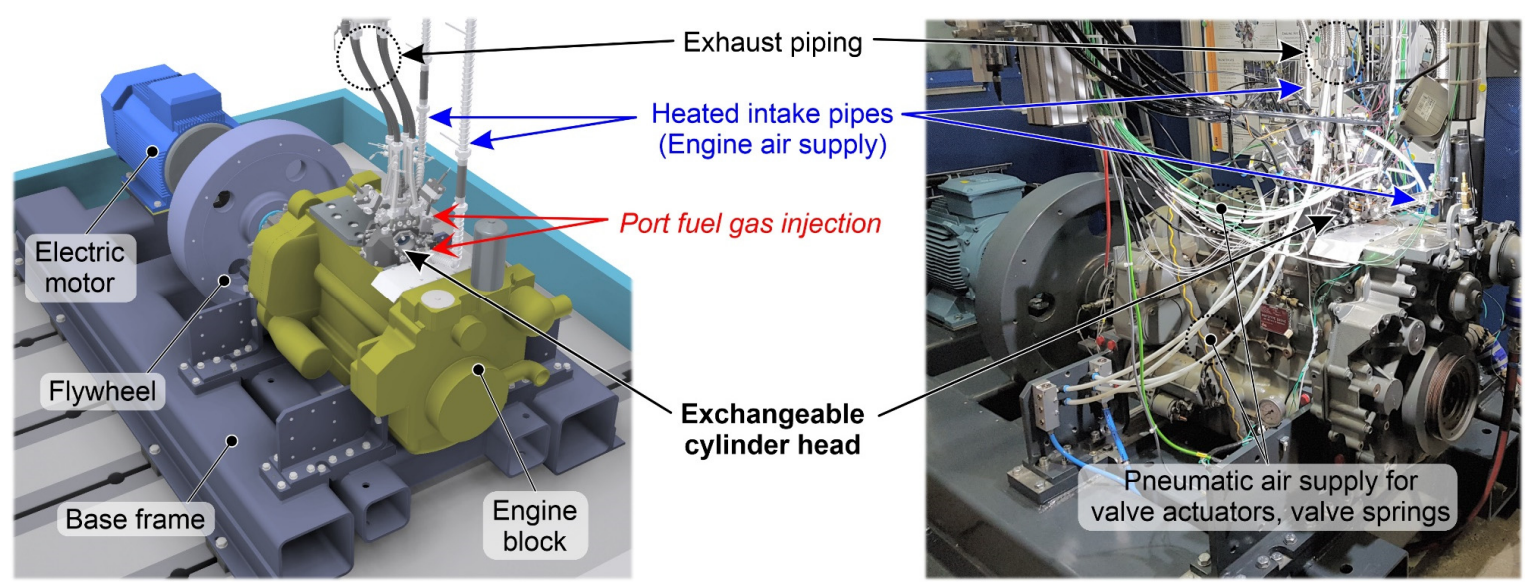

Figure 4. An overview of the new test rig: (left) the CAD design and (right) the real setup including all cables, pipes, pressurized air supply tubes, etc. 
Combustion chamber: To reach sufficiently high compression pressures and temperatures, the size of the combustion chamber has been fixed at $\varnothing 60 \mathrm{~mm}$ diameter and $20 \mathrm{~mm}$ depth.

Connection with the engine cylinder (neck): The neck has the same cross section as the combustion chamber itself $(60 \mathrm{~mm} \times 20 \mathrm{~mm})$. Since this forms a "dead volume" that reduces the compression ratio, the length of the neck is kept at a minimum. Two factors limit this length: Firstly, the optical path through the circular and the side windows should not be blocked by engine or engine head components. Secondly, the rim around the cylinder head neck must be stiff enough to ensure that the prescribed contact pressures of the cylinder head gasket is maintained even under full load.

Gas exchange valves: There are four fully variable, pneumatically actuated valves (Ø16 mm).

Air supply: The engine intake air (pressure up to 7 bar) can be preheated to temperatures $>200{ }^{\circ} \mathrm{C}$ to reach the desired end of compression gas pressure and temperature.

Fuel gas supply: For experiments in the context of premixed- or dual/multi-fuel combustion, the (usually gaseous) fuel can be injected into the air supply pipes just before the intake valves. The timing of this injection is coupled to the timing of the intake valves; metering is done by controlling the injection duration and the fuel pressure.

Thermal conditioning: An external unit is used to control the water temperature and flow rate in the engine blocks cooling circuit. The water is also used to heat and cool the engine oil, respectively.

Engine block motoring and drive train: An electric motor/generator is used to control the engine speed. To reduce speed variations, a large flywheel (moment of inertia $48 \mathrm{kgm}^{2}$ ) is mounted in the shaft connecting the electric motor and the engine block.

Engine piston: The piston bowl of the piston in the actually used cylinder is filled in to reduce the compression volume. For safety reasons, valve pockets have been machined into the piston; no collision between intake valves and the piston can occur (the exhaust valves are far away from the piston).

Control system: An FPGA (field-programmable gate array)-based system controls gas exchange valve timing and other crankshaft position dependent signals (liquid and gaseous fuel injection, triggers for experimental devices). Another, PLC (programmable logic controller)-based system, is used to control temperatures, various pressures and the electric motor. It also monitors all safety relevant signals and shuts down the test rig in case of an error.

Compression volume: Figure 5 shows the dimensions of the in-cylinder and combustion chamber volume of the currently realized cylinder head configuration. The total end of compression volume amounts to $155,600 \mathrm{~mm}^{3}$, which results in a compression ratio of 13.8 .
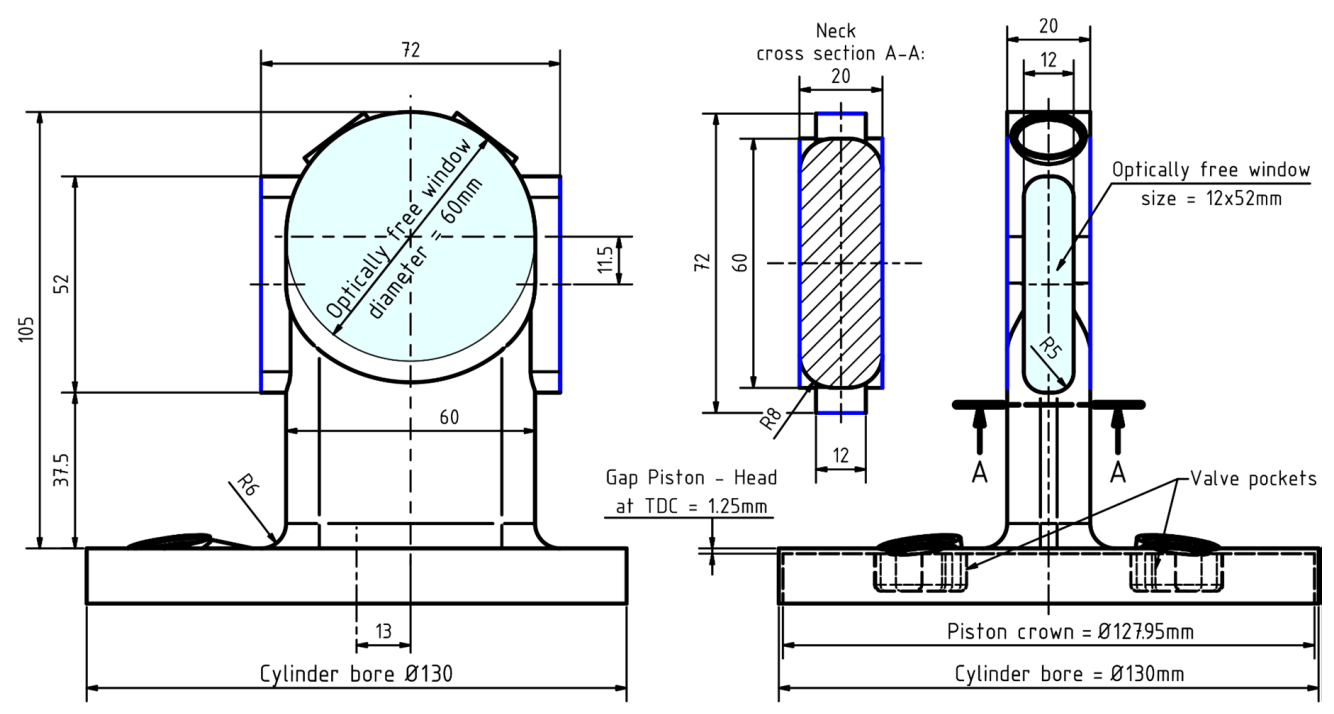

Figure 5. Dimensions of the internal volume of the optical cylinder head (at TDC piston position). For the base configuration, the total internal volume amounts to $155,600 \mathrm{~mm}^{3}$ (compression ratio 13.8). 


\subsection{Gas Exchange Valves}

The space available for the gas exchange valves is quite limited since the emphasis in the design was put on optimal optical access. There are two intake valves $(\varnothing 16 \mathrm{~mm})$ going directly into the engine cylinder, and two exhaust valves (Ø16 $\mathrm{mm}$ as well) sitting on top of the combustion chamber, as shown in Figure 6.

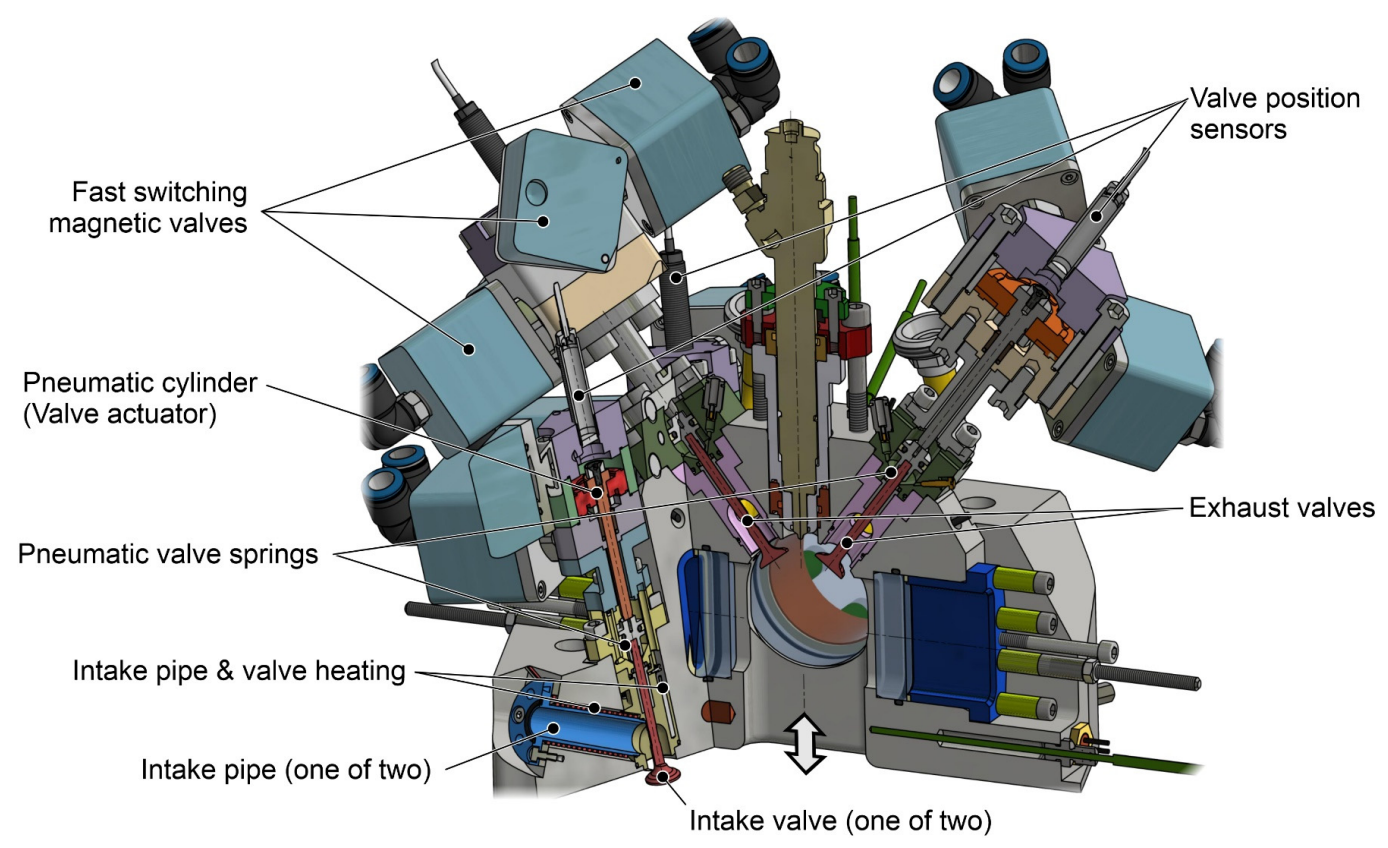

Figure 6. The pneumatically operated intake and exhaust valves. Multiple, fast switching pneumatic valves are used for each cylinder to open and close the gas exchange valves as quickly as possible.

Pneumatic cylinders are used to open the valves; adjustable pneumatic springs close the valve at the end of the gas exchange. To realize faster and better controllable valve closing times, the pneumatic pistons are actively pushed back as well. Throttle valves and end position damping in the pneumatic cylinders ensures smooth valve closing and prevents hard impacts of the valves on the valve seats.

The gas exchange valves are not intended to operate as real engine valves; they open and close as quickly as possible to maximize the achievable gas flow rates (trapezoidal valve lift curves; opening time about $5 \mathrm{~ms}$; closing time about $8 \mathrm{~ms}$ ). For this, each engine-valve actuation cylinder is equipped with multiple fast, high flow rate pneumatic valves (Bibus Matrix series 750). Each engine-valve is equipped with a valve lift sensor; those signals are used in the control system to monitor effective valve opening and closing times. The valves can be opened at any time during engine cycles; valve pockets in the piston prevent collisions between the intake valves and the piston.

The gas flow through the engines gas exchange valves is very fast and highly turbulent. To prevent high temperature losses of the preheated intake air-gas mixture passing the engine intake valves, they can be electrically heated to up to $200^{\circ} \mathrm{C}$.

\subsection{Optical Access, Experimental Configurations}

Depending on the location of the injection (or ignition) source, two different basic configurations are used (see Figure 7). In the first configuration (" $\mathrm{C}$ " for central position), one of the circular windows is replaced with a metal holder to mount the injection and ignition source. A special holder with an integrated high temperature mirror allows the use of the double pass Schlieren imaging technique in this configuration. The second basic configuration (" $\mathrm{T}$ " for top position), with injection and ignition from the top, allows full, "see through" optical access to the combustion chamber through the large, circular windows and the smaller rectangular windows on the side. 


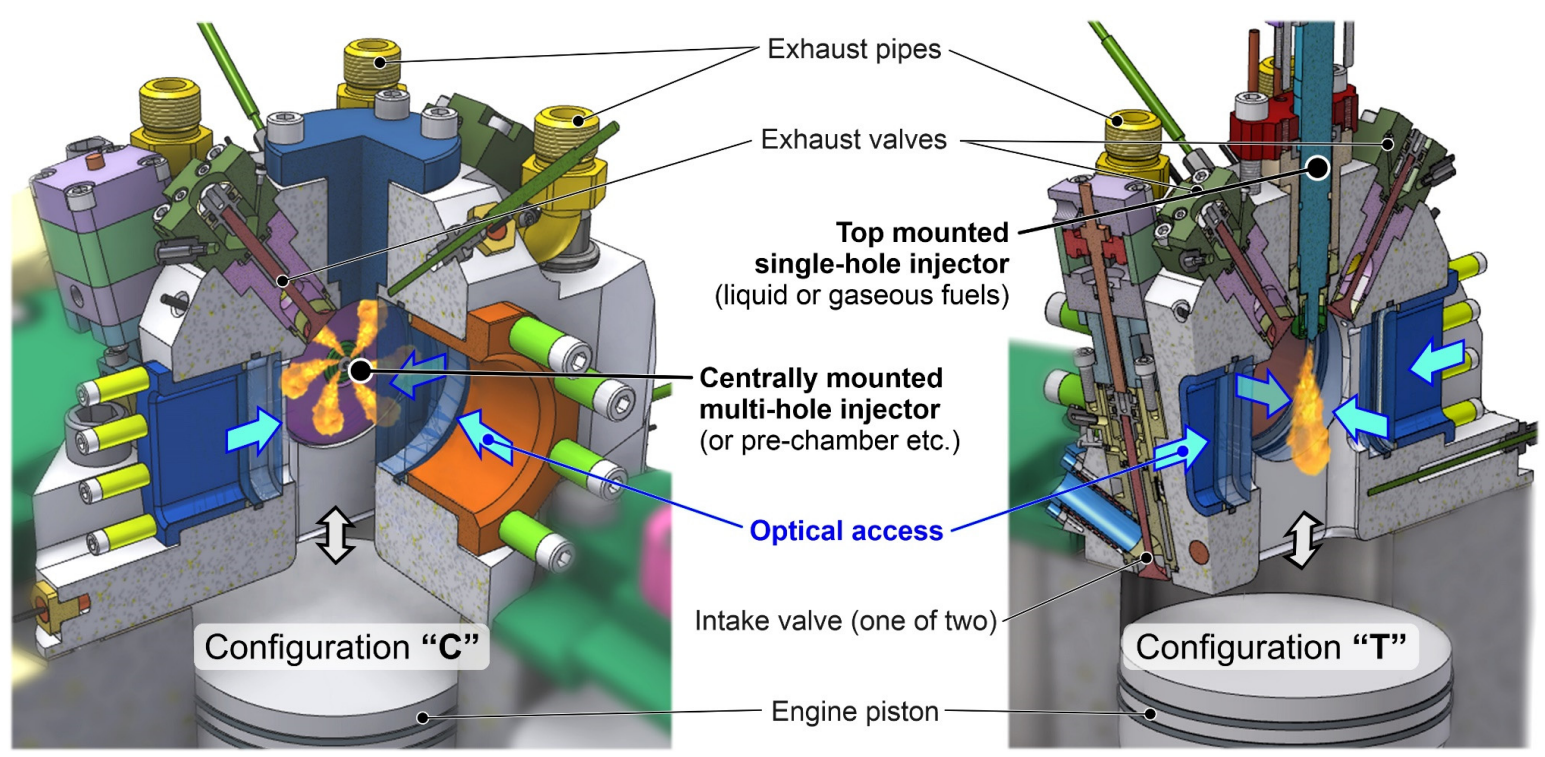

Figure 7. The two basic configurations of the test rig: (left) the setup with a central multi-hole injector/prechamber/ignition source mounted in place of one of the circular windows (configuration "C"); and (right) the configuration with the injection/prechamber/ignition source mounted on top of the cylinder head. This configuration provides "see through" optical access from two directions and maximizes the observable fuel spray/gas-jet length.

\subsection{Standard Instrumentation}

The standard equipment used for pressure measurements in all experimental campaigns consists of an M8 piezo electric sensor (Kistler 6044 anti-strain type) mounted in the engine cylinder, an M5 piezo electric sensor (Kistler 6052CU40) mounted in the optically accessible combustion chamber and two M14 piezo resistive pressure sensors (Kistler 4049B) mounted before the two intake valves (see also Section 4.1).

The intake air-gas mixture temperature is measured with standard thermocouples (K type, $\varnothing 1$ $\mathrm{mm}$, external junction) in the air stream; the intake air mass flow is determined with a Coriolis mass flowmeter (type Endress \& Hauser Promass 80F DN15). To isolate the mass flow meter from the large pressure fluctuations in the intake air piping system, it is installed in front of a large pressure oscillation-damping vessel. Although this arrangement greatly reduces the mass flow fluctuations in the flow meter, it also requires a long time (typically 100 cycles) to reach stable conditions necessary for accurate measurements.

The crankshaft position is measured with a photo sensor and a slotted disk (1200 slits $=0.3^{\circ}$ resolution) mounted on the engine's flywheel. The FPGA control system uses a PLL (phase locked loop) to generate a crankshaft position signal with $0.1^{\circ}$ resolution from the optical angle encoder signals. This crank angle resolution is used for all crank angle related control signals and measurements.

\subsection{Technical Data of the Flex-OeCoS}

Table 1 presents the technical data of the base engine block used for the Flex-OeCoS. Three of the four Liebherr D944 engine cylinders are closed off, only one cylinder is in use. 
Table 1. Engine block data.

\begin{tabular}{cc}
\hline Dimension, Operating Parameter & Value \\
\hline Cylinder bore & $\varnothing 130 \mathrm{~mm}$ \\
Stroke length & $150 \mathrm{~mm}$ \\
Connecting rod length & $237.1 \mathrm{~mm}$ \\
Displacement per cylinder & $1990 \mathrm{~cm}^{3}$ \\
Gap height & $1.25 \mathrm{~mm}^{1}$ \\
Max. engine speed & $1800 \mathrm{rpm}^{2}$ \\
Max. cylinder pressure & $230 \mathrm{bar}$ \\
Operating temperature of water and oil & $80^{\circ} \mathrm{C}^{3}$ \\
\hline
\end{tabular}

${ }^{1}$ Measured at TDC from piston top to the bottom of the head. ${ }^{2}$ Normal operating range: $300-1200 \mathrm{rpm} .{ }^{3}$ Controlled with an external unit.

The key component of the new test rig is the easily exchangeable and adaptable cylinder head/combustion chamber. Initially, the "Car" type cylinder head has been realized; the corresponding technical data are summarized in Table 2.

Table 2. Cylinder head data (current "Car" configuration).

\begin{tabular}{cc}
\hline Dimension, Operating Parameter & Value \\
\hline Chamber bore diameter & $\varnothing 60 \mathrm{~mm}$ \\
Chamber and neck depth & $20 \mathrm{~mm}$ \\
Neck width & $60 \mathrm{~mm}$ \\
Neck length & $45 \mathrm{~mm}^{1}$ \\
Cylinder head heating temperature: & $\leq 200 \mathrm{C}^{2}$ \\
Total Internal volume: & $155,600 \mathrm{~mm}^{3}$ \\
Compression ratio: & 13.8 \\
\hline
\end{tabular}

\footnotetext{
${ }^{1}$ Measured from the circular combustion chamber to the bottom of the head. ${ }^{2}$ Electrical heating, which can be switched off during experiments.
}

The test rig is supplied with externally compressed air that is electrically heated in the two 3-m-long intake pipes leading to the two intake valves. The key parameters of the air supply system and the gas exchange valves are presented in Table 3.

Table 3. Air supply and gas exchange valve data.

\begin{tabular}{cc}
\hline Component, Operating Parameter & Value \\
\hline Engine valves & $2 \times$ intake, $2 \times$ exhaust valves $\varnothing 16 \mathrm{~mm}$ \\
Engine valve operation & Pneumatic valve actors, fully variable timing \\
Valve lift curve & Trapezoid, fully open in $\approx 5 \mathrm{~ms}$, closed in $\approx 8 \mathrm{~ms}$ \\
Intake pressure range & $\mathrm{p} \leq 7 \mathrm{bar}$ \\
Intake air temperature range & $>200^{\circ} \mathrm{C}$ \\
Intake valve heating temperature & $\leq 200^{\circ} \mathrm{C}$ \\
\hline
\end{tabular}

\subsection{Structure of Experiment Sequences}

As mentioned above, multiple intake cycles are required to prepare the desired gas mixture in the cylinder prior to the actual experiment cycle(s). Usually multiple exhaust cycles are required to completely empty/flush the cylinder volume as well to reach reproducible conditions in all experiment cycles.

As shown in Figure 8, up to five consecutive sequence types can be used in experiments:

- Each sequence type has its own, separate gas exchange valve timing and experimental trigger setting.

- $\quad$ Each sequence type can be repeated several times if desired. 
- In some sequence types, the valves for adding gaseous fuels into the air intake can be activated as well.

- More trigger outputs are available in the actual experiment sequence type to control measurement devices and, if needed, fuel injection and/or ignition systems.

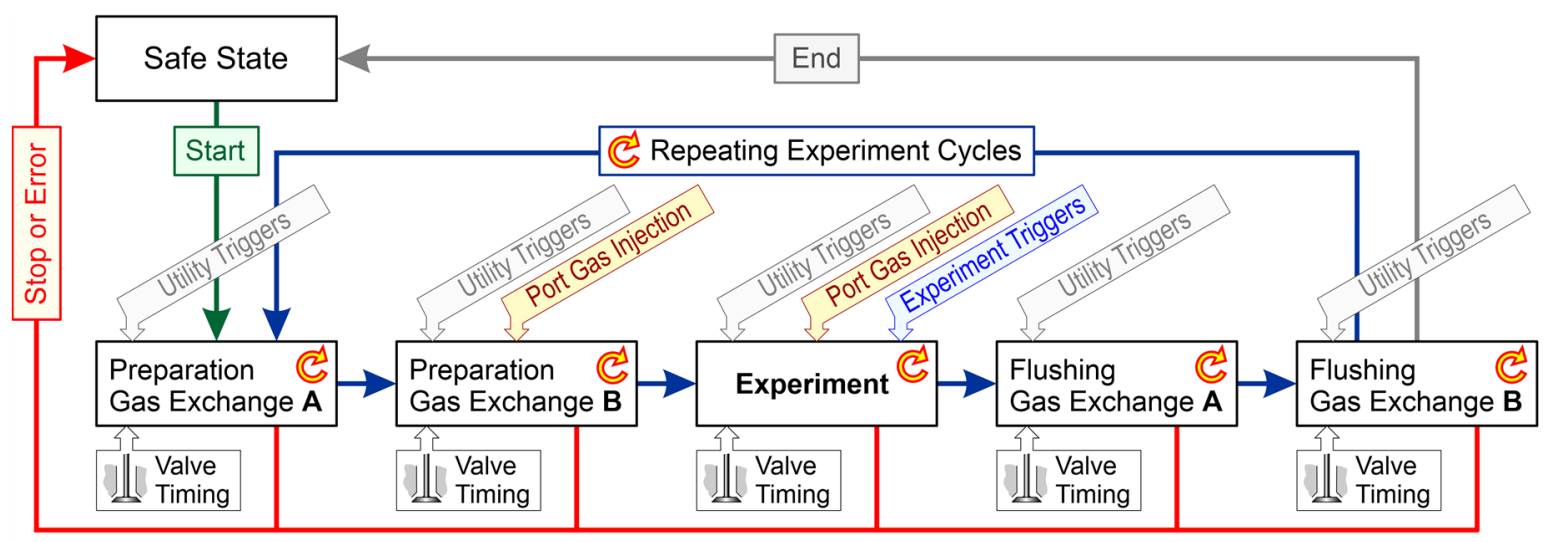

Figure 8. Basic structure of experiment cycles in the Flex-OeCoS.

The complete cycle of the consecutive sequences can be repeated several times if desired. However, the following possibly limiting factors must be considered:

Cylinder-and combustion chamber wall temperatures: Due to the inflow of preheated intake air and the gas temperature increase from compression and (in most experiments) combustion, the wall temperature in the combustion chamber and engine cylinder will rise over time (so far there is no active cooling of the cylinder head). To slow down this temperature rise, the electrical cylinder head heating can be switched off during the experiment cycles. Further, the compression ratio in the gas exchange sequences can be reduced with an early opening of the exhaust valves.

Stable pressure levels and air mass flow: To achieve stable, repeatable conditions and a constant air mass flow during the experiments cycle repetitions, it is necessary to optimize valve timing in the gas exchange sequences to reach the same air mass flow. This way a stable pressure distribution can establish itself in the intake piping system.

Minimum cylinder pressure: The pressure in the cylinder must never fall below ambient pressure during the operation of the engine to prevent lube oil intrusion into the cylinder/combustion chamber.

Initial in-situ analysis: After an experiment cycle has finished, the control system will immediately present a graphical overview of important experimental parameters such as mass flows, cylinder pressures, peak pressures (i.e., pressure and corresponding crank angle), wall temperatures and calculated approximate ignition delays of all recorded cycles. The operator thus immediately receives a feedback that allows him to check if the actual experimental conditions have been correct, and how the conditions changed in the course of the measurement.

\section{Characterization of the Flex-OeCoS Test Rig}

It is important to characterize a new test rig after its commissioning: Firstly, it must be ensured that its desired performance regarding experimental conditions (pressures, temperatures, flow, and reproducibility) can be achieved. Secondly, it is needed to obtain the test rig settings (valve timings, sequence repetitions, wall/air heating temperatures, etc.) required to realize the actually desired experimental conditions (pressures, temperatures, flow). Thirdly, a database can be created that contains all measured quantities for different settings of the desired experimental conditions. This database can be used in future projects to validate and tune models in accompanying CRFD simulations in the test rig. 
The following sections present the results of the assessment of the test rig regarding cylinder and combustion chamber pressures, measurements of the actual gas temperatures in the combustion chamber using fine wire thermocouples and, lastly, measurements of the flow field in the combustion chamber using 2D high speed PIV (particle image velocimetry). Unless noted otherwise, the standard settings, as shown in Table 4, are used for the measurements presented here.

Table 4. Standard measurement conditions. Combustion TDC defined at $0^{\circ} \mathrm{CA}$ (crank angle).

\begin{tabular}{cc}
\hline Operating Parameter & Value \\
\hline Engine speed (motored) & $600 \mathrm{rpm}$ \\
Peak compression pressure & $100 \mathrm{bar}^{1}$ \\
Intake valve timing & Open $-370^{\circ} \mathrm{CA}$, close $-180^{\circ} \mathrm{CA}$ \\
Exhaust valve timing & Open $180^{\circ} \mathrm{CA}$, close $-370^{\circ} \mathrm{CA}$ \\
Cylinder head/intake valve temperature & $150^{\circ} \mathrm{C}$ \\
Intake manifold air temperature & $150{ }^{\circ} \mathrm{C}^{2}$ \\
\hline
\end{tabular}

${ }^{1}$ Intake pressure adjusted accordingly. ${ }^{2}$ Target peak compression temperature $1000 \mathrm{~K}$.

Starting from those standard settings, measurements with a variation of engine speeds, peak compression pressures and peak compression temperatures have been carried out. Due to small modifications in the ongoing test rig commissioning process, the actually used intake manifold air pressure and temperature varied slightly over time in these initial measurement campaigns.

\subsection{Cylinder Pressure Measurements}

Measurements of the cylinder pressure form the basis of heat release calculations and other combustion diagnostics regarding variability, knock detection, etc. Therefore, it is important to achieve a maximum accuracy in all parts of the pressure measurement setup. This applies even more to the new test rig, since it will also be used for the further development of pressure sensing devices and related equipment.

The in-cylinder volume of the Flex-OeCoS has a quite uncommon configuration: the optically accessible combustion chamber on top is attached to the actual engine cylinder as an oversized prechamber. This leads to a two-stage combustion under premixed/dual-fuel conditions since the fuel in the actual engine cylinder only starts to burn after the flame has passed through the "neck" that connects the two volumes. Pressure compensation between the two volumes is not instantaneous; therefore, both pressures must be measured individually.

The cylinder head of the Flex-OeCoS has mounting holes for up to four M 5 piezoelectric pressure transducers in the optically accessible combustion chamber and two M 8 sensors in the engine cylinder. For experiments where the optical accessibility is less important than pressure signals, the radial and/or axial windows can be replaced with inserts that provide space for up to six additional pressure sensors per insert. In Figure 9a, the inside volume of the Flex-OeCoS is shown with pressure sensors mounted in all standard locations in the cylinder head and in two sensor inserts mounted instead of windows (piston position $20 \mathrm{~mm}$ before TDC).

A specially designed, thermal-oil cooled sensor adapter for use in the Flex-OeCoS test rig is shown in Figure 9b. The heat fins and cooling path arrangement optimize heat transfer and heat distribution in the adapter, respectively, aiming for a uniform sensor temperature during experiments. Due to its complicated shape, it is manufactured with the selective laser melting technique. A subsequent heat treatment increases the mechanical strength of the insert and reduces the strain on the package. Thanks to the wide operating temperature range of the thermal oil that is used as a coolant, it is possible to realize both positive and negative heat transfers from the insert and pressure sensor to and from the gas in the combustion chamber, respectively. 


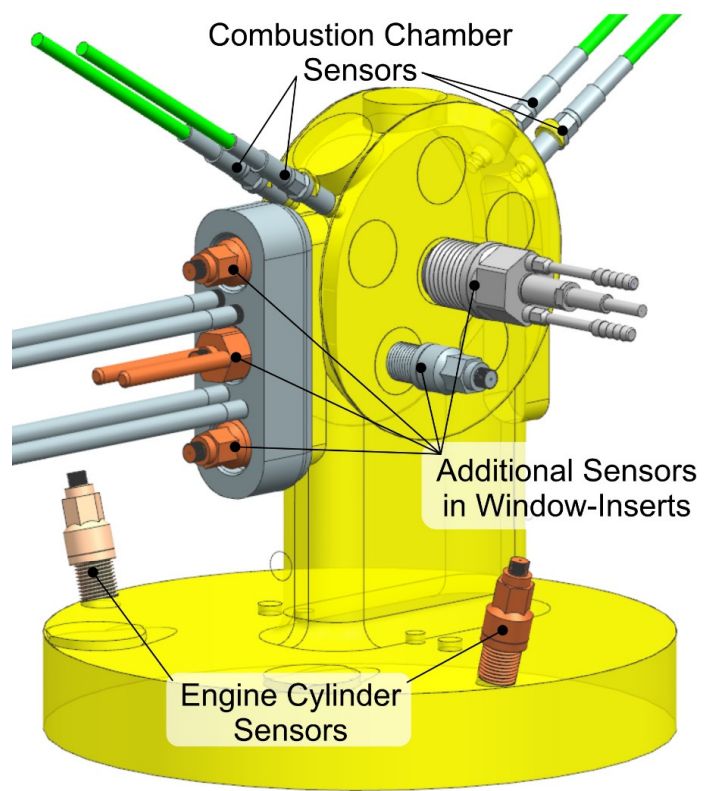

a)

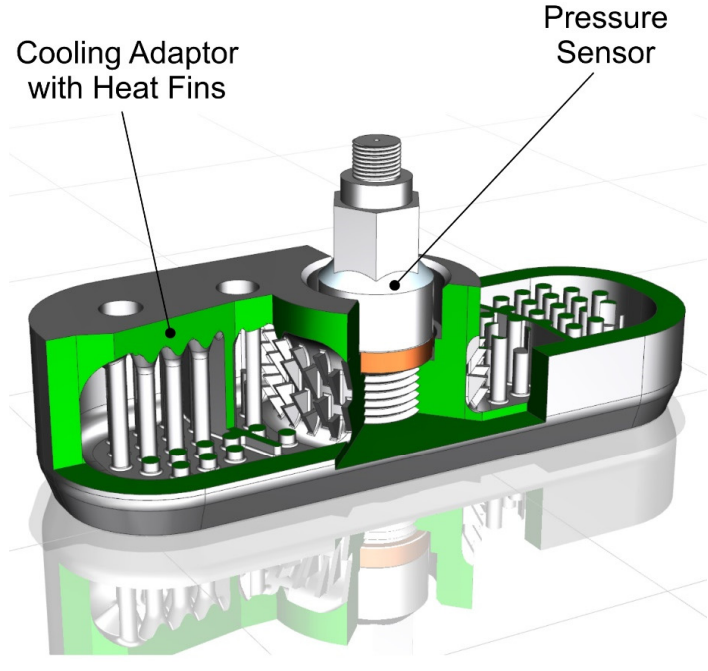

b)

Figure 9. (a) The inside (gas) volume of the engine cylinder (piston $20 \mathrm{~mm}$ before TDC) and the combustion chamber with pressure sensors mounted in all standard locations plus two inserts.

(b) Window insert for a single, thermally especially well stabilized pressure sensor.

Pegging of the Cylinder Pressure

Piezo-electric pressure sensors, as are normally used to measure cylinder pressures, must be tied to a known absolute pressure to obtain the effective in-cylinder pressure. The most common pegging methods are either based on a thermodynamic calculation assuming a fixed polytropic exponent within a part of the engine cycle, or based on the assumption that the cylinder pressure is equal to the intake manifold pressure at a certain point during the engine cycle [26]. In the case of the Flex-OeCoS, the first method is difficult to apply due to the different wall-heat transfer regimes in the engine cylinder, the optically accessible combustion chamber and the connecting "neck" in-between. The second method cannot be applied easily as well because the gas exchange valves are very small compared to normal engine valves, thus the two pressures are never equal during a cycle.

To develop the appropriate pegging method for the new test rig, an experimental campaign was carried out that used an additional high fidelity, absolute pressure sensor mounted in the optically accessible combustion chamber to measure the effective chamber pressure for different engine speeds and intake with respect to peak compression pressures. It was found that, within a certain crank angle range near BDC (bottom dead center), there is a consistent linear relation between intake manifold pressure and chamber pressure. Thus, in future measurement campaigns, tabulated coefficients can be used to peg the cylinder pressure to the absolute intake manifold pressure in the defined crank angle range. The set of coefficients depend on both engine speed and valve timings.

Through comparisons with measurements using reference pressure sensors, it is possible to estimate the uncertainty of the measurements when using the standard instrumentation only. At a typical load point, as shown in Figure 10, the estimated maximum measurement error of the cylinder with respect to combustion chamber pressure is in the order of $30 \mathrm{mbar}$ during the gas exchange phases, 50 mbar during the compression and expansion stroke (without combustion) and 100 mbar during the combustion phase. 


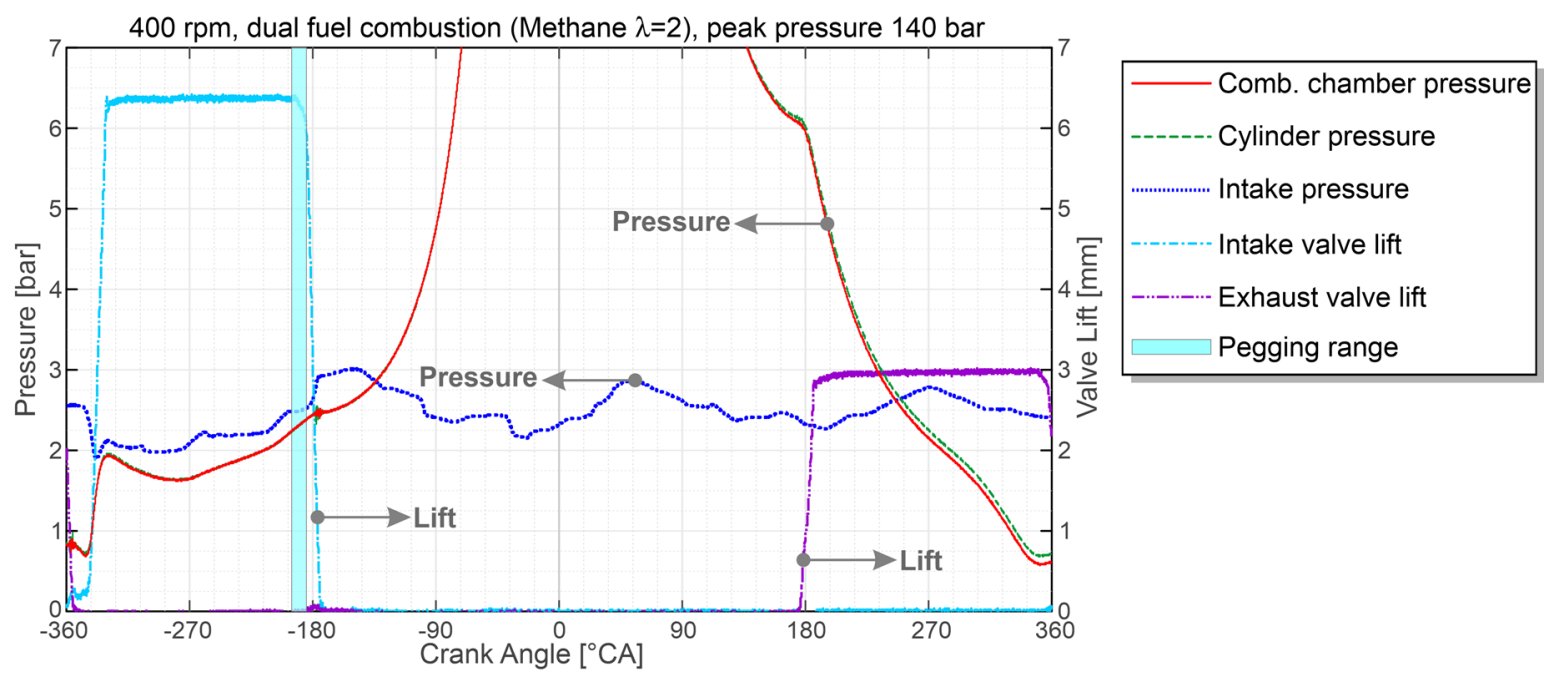

Figure 10. Pressure traces and valve lift curves for an experiment with combustion ( $400 \mathrm{rpm}$, premixed fuel methane $\lambda=2$, pilot injection with dodecane, peak combustion pressure $140 \mathrm{bar}$ ). In the blue colored area (around $-190^{\circ} \mathrm{CA}$ ), the cylinder pressure can be pegged to the absolute intake pressure with the help of tabulated coefficients.

\subsection{Gas Temperature Measurements}

Since direct measurements are difficult, the actual gas temperature in combustion engines is usually calculated with the help of heat release calculations. For well-known standard engine configurations, this works quite well, but, for the new test rig with its two large, separate combustion chambers, it is rather more difficult. Therefore, to gain better knowledge about the effective gas conditions inside the combustion chamber of the Flex-OeCoS, detailed temperature measurements have been carried out [27]. These measurements also form a good basis for the development of the heat release calculation code intended to be used for the new test rig.

Tracking the rapid changes of the working gas temperature inside internal combustion engines requires robust sensors with very low response times. Only TCs (thermocouples) consisting of very thin sensor wires $(\leq 25 \mu \mathrm{m})$ with exposed welding beads are fast enough to keep up with the rapid changes of the gas temperature inside the cylinder. Owing to the fragility of those sensors, all measurements were carried out without combustion.

Due to the heat transfer processes between the gas and the thermocouple, the measurements have a certain response time (lag) relative to the actual gas temperature change. Especially in very unsteady environments as in the cylinder and combustion chamber of IC engines, this can lead to highly delayed and inaccurate sensor readings—as illustrated by the $\varnothing 0.5 \mathrm{~mm}$ TC temperature measurement shown in Figure 11.

In principle, the response time of a thermocouple measurement can be described by a first-order differential equation: $T_{g}-T=\tau \cdot \partial T \partial t$, where $T_{g}$ is the actual gas temperature, $T$ is the thermocouple temperature and $\tau$ is the thermocouple time constant. However, the time constant $\tau$ is not just a fixed property of the thermocouple but depends heavily on the gas state and gas flow around it as well. To overcome this, multiple techniques for thermocouple response time estimations have been proposed in the literature. All are based on the simultaneous measurement with two thermocouples that have different wire diameters but are positioned in close proximity, so they are exposed to the same gas state and flow condition. For the measurements presented here, the best results were found using a technique based on $[28,29]$. Figure 11 shows a comparison between the measured thermocouple temperatures (TC diameters $12.5 \mu \mathrm{m}$ and $25 \mu \mathrm{m}$ ) and the reconstructed actual gas temperature (measurement position in the center of the combustion chamber). 


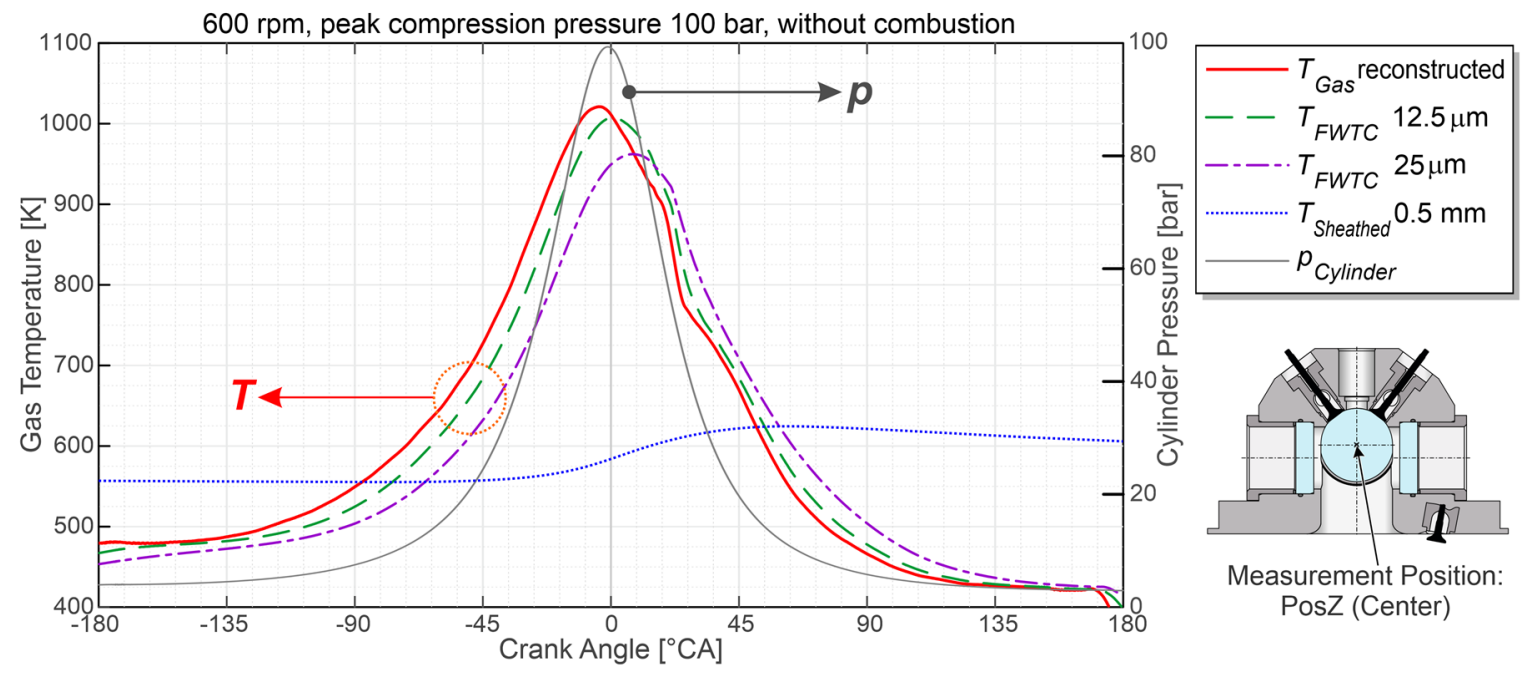

Figure 11. Traces of the measured temperatures (thermocouples $\varnothing 12.5 \mu \mathrm{m}$ and $\varnothing 25 \mu \mathrm{m}$ ) and the reconstructed actual gas temperature. For comparison, the temperature that is measured with a common $\varnothing 0.5 \mathrm{~mm}$ sheathed thermocouple is shown as well (blue dotted line).

The new test rig is highly flexible in multiple respects: gas conditions in the cylinder and combustion chamber regarding temperature, pressure, and flow characteristics can be varied over a wide range by adjusting intake manifold pressure, temperature, (gaseous) fuel content, cylinder head heating, valve timing, and engine speed. This allows optimizing the experimental environment for investigations using various fuel types, fuel delivery to ignition systems, and combustion processes.

Figure 12 shows the measured (not reconstructed) gas temperatures $(\varnothing 12.5 \mu \mathrm{m}$ TC) in the combustion chamber at two locations for a variation of the intake air preheating temperature. The temperature at the position near the top (Pos 1, $26 \mathrm{~mm}$ from the center) is about $40 \mathrm{~K}$ lower compared to the center of the combustion chamber (Pos Z), both located in the middle plane (between the large circular windows). Since the end-of-compression pressure was kept at 100 bar in all cases (by adapting the intake air pressure), this temperature variation is also a density variation. Since intake pressure and temperature can be varied independently, constant density conditions at different gas temperatures can be realized as well.

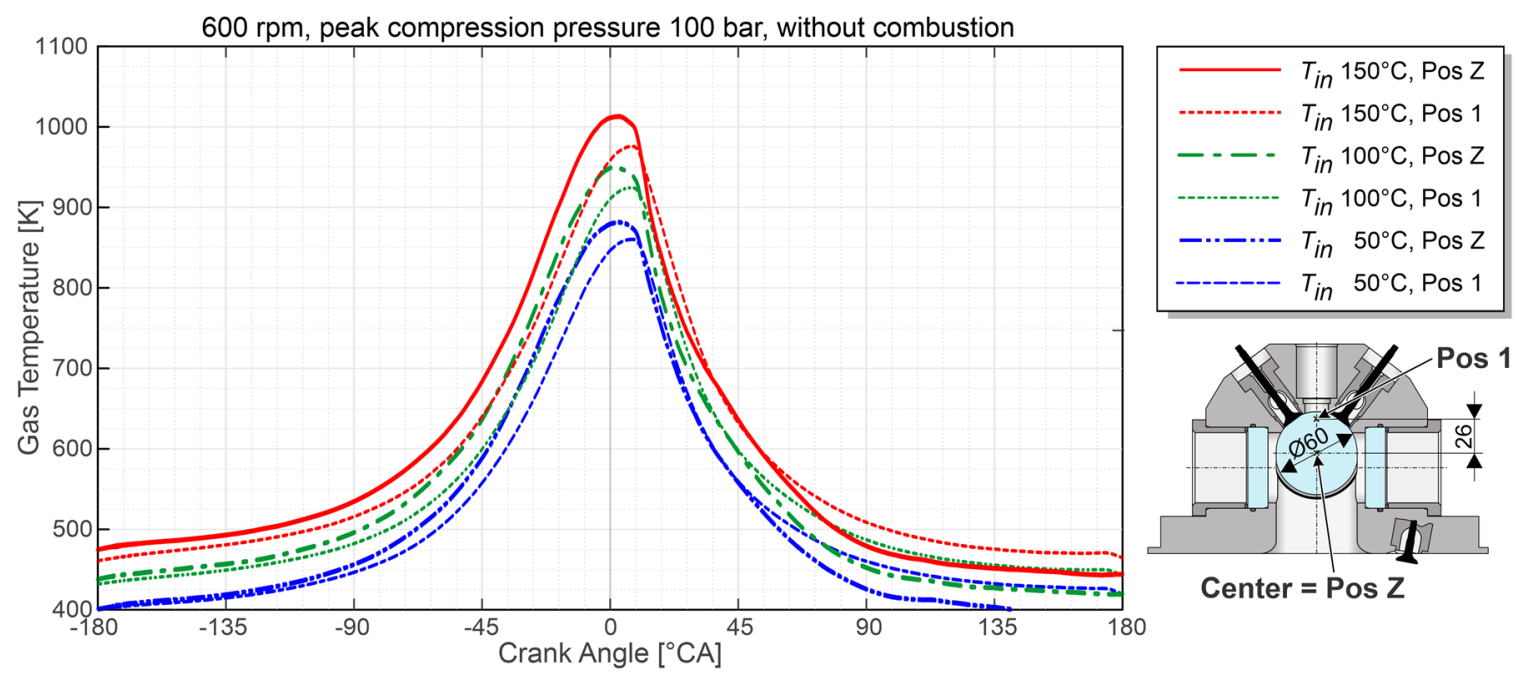

Figure 12. Measurement of the gas temperature (with a single $\varnothing 12.5 \mu \mathrm{m}$ TC) at two locations inside the combustion chamber. The variation of the preheated intake air temperature $T_{\text {in }}$ results in a density variation, since the peak compression pressure was kept at 100 bar for all cases. 
The reconstructed temperature in the center of the combustion chamber allows defining the temperature operation point in experiments. Still ongoing, however, is the analysis of a full series of measurements that are required to obtain a full spatial temperature distribution field in the combustion chamber. This will benefit both further experimental campaigns and the accompanying CRFD simulations.

Another field of interest closely related to accurate in-cylinder gas temperature measurements is the delicate matter of wall heat fluxes, as well as the measurement thereof. By using near-wall measurements of the actual gas temperature, combined with fast and precise wall temperature measurements, it is possible to calculate the local heat flux to and from the wall with the "Zero Crossing Method" (German: "Nulldurchgangsmethode" [30]). Detailed studies are currently under way to measure the wall heat fluxes in the Flex-OeCoS test rig with this method and then, in combination with the PIV flow field measurements, to develop appropriate wall heat transfer models that can be used in heat release calculations and CFD simulations of the new test rig.

\subsection{Flow Field Measurements using PIV}

Due to its rotated orientation in the new test rig, the flow field inside the combustion chamber is different from the in-cylinder flow fields in normal engines. Swirl in the engine cylinder would become tumble in the combustion chamber, and vice versa. However, large structures break up while passing through the "neck" that connects the two volumes (except if they are aligned with the long side of the "neck"). Therefore, the flow in the combustion chamber is quite different from and largely independent of the flow field in the actual engine cylinder.

Since good knowledge about the flow field in the combustion chamber is important, a high speed PIV measurement campaign was carried to assess flow-field, flow-structures, flow-velocities and turbulence levels for a variation of engine speeds and intake and therefore peak compression pressure levels [31]. All experiments have been carried out without combustion. An overview of the experimental setup is shown in Figure 13.

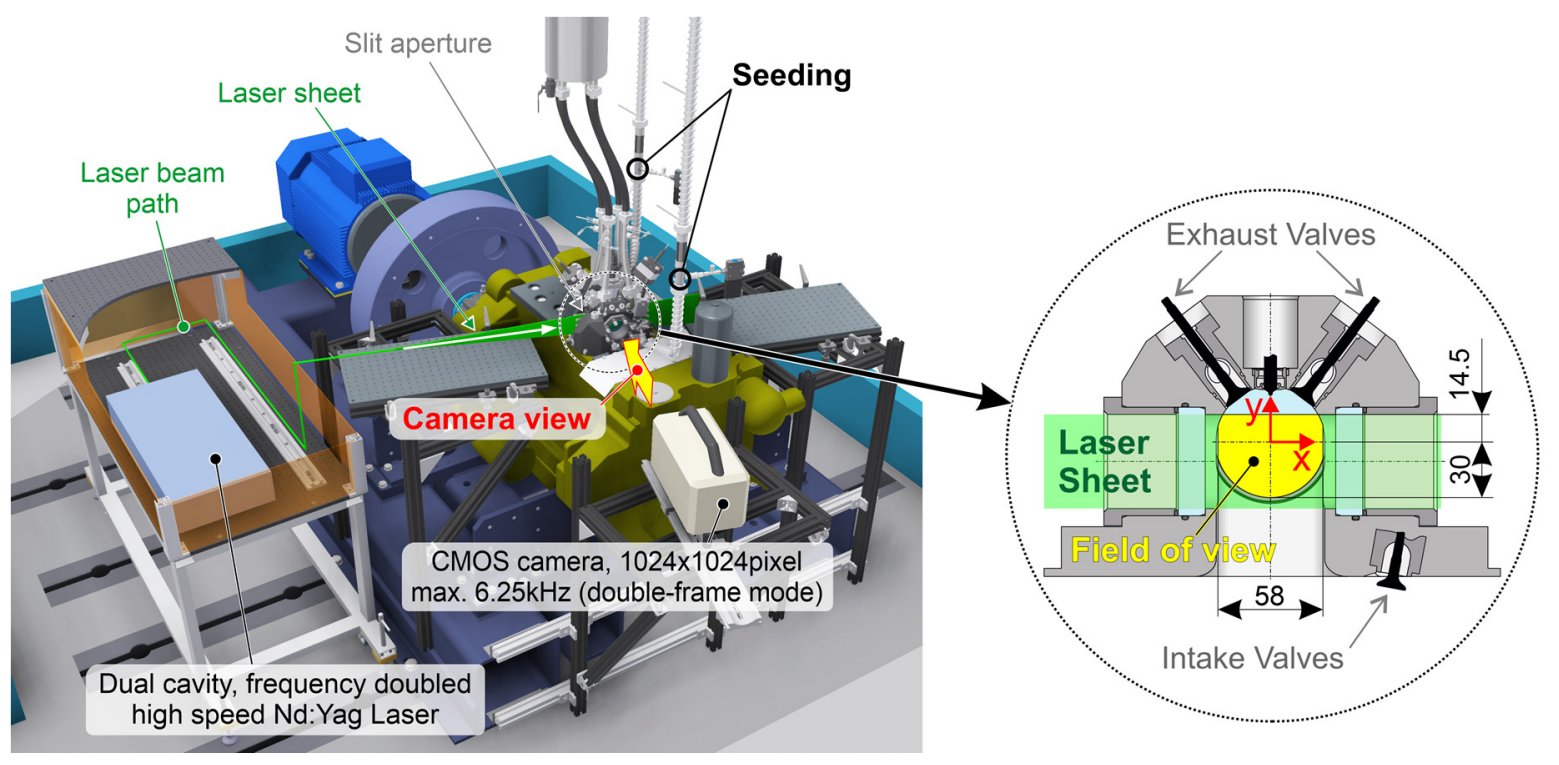

Figure 13. Optical setup for the PIV flow field measurements in the Flex-OeCoS.

Laser sheet: The laser from a dual cavity, frequency doubled Nd:YAG laser (Photonic Industries DM60 $532 \mathrm{DH}, 6 \mathrm{~mJ} /$ pulse, $200 \mathrm{~ns}$ pulse width) is transformed into a light sheet ( $45 \mathrm{~mm}$ wide, $0.5 \mathrm{~mm}$ thickness) by using lenses and a slit aperture just in front of the cylinder head. The light sheet (i.e., measurement plane) is aligned along the center of the combustion chamber. 
Seeding: To reduce abrasive wear in the engine, particles made of boron nitride have been chosen instead of the more commonly used titan dioxide particles. With a mean diameter of $1 \mu \mathrm{m}$, they are able to follow the flow structures very well (relaxation time $\leq 5 \mu$ s, Stokes number $\sim 10^{-5}$ (engine time scale $\tau_{e}=$ Stroke length/Mean piston speed)). The particles are seeded into the intake air with four separately activated blowpipes, as shown in Figure 13.

Camera: A 12-bit monochrome CMOS camera (Photron FASTCAM SA-X2) equipped with a $105 \mathrm{~mm} \mathrm{f} / 4$ Micro-NIKKOR objective was used to record the seeding particles. The chosen field of view (seen on the right in Figure 13) results in a resolution of approximately 17 pixels per $\mathrm{mm}$.

Timing: A double image of the particles was recorded at every crank angle. The crank angle dependent time delay between the pulses from the two laser cavities was optimized towards maintaining an average particle displacement of five pixels between the double images.

Post-processing: The raw PIV images have been processed with commercially available software (LaVision, DaVis 8.4). A particle intensity normalization filter was used to eliminate the local background noise before the calculation of the flow velocities from the double images with a multi-pass, cross-correlation algorithm. The interrogation window size was set to $24 \times 24$ pixels with $50 \%$ overlap. The resulting two-dimensional velocity field has a vector spacing of $0.71 \mathrm{~mm}$.

Starting from the standard point (600 rpm and 100 bar peak pressure), measurements with an engine speed variation (400 and $800 \mathrm{rpm}$ ) and a peak compression pressures variation (70 and $130 \mathrm{bar}$ ) have been made. The intake air temperature was kept constant at $200^{\circ} \mathrm{C}$ for all cases; the intake air pressure was adjusted for each parameter set to reach the desired peak compression pressure.

PIV data have been acquired at every crank angle over $N=200$ individual cycles for each parameter set. The ensemble averaged mean velocity $\vec{u}_{\text {ens }}$ was then calculated for every crank angle $\theta$ over all $N$ cycles:

$$
\vec{u}_{\text {ens }}(\theta)=\frac{1}{N} \sum_{k=1}^{N} \vec{u}^{(k)}(\theta)
$$

The corresponding turbulence intensity $\vec{u}_{\text {ens }}^{\prime}$ at the crank angle $\theta$ is:

$$
\vec{u}_{\text {ens }}^{\prime}(\theta)=\sqrt{\frac{1}{N} \sum_{k=1}^{N}\left(\Delta \vec{u}^{(k)}(\theta)\right)^{2}}
$$

where $\Delta \vec{u}^{(k)}(\theta)$ is the difference between the instantaneous velocity $\vec{u}^{(k)}$ at the crank angle $\theta$ in the current cycle $k$ and the ensemble averaged velocity $\vec{u}_{\text {ens }}$ at the same crank angle $\theta$ :

$$
\Delta \vec{u}^{(k)}(\theta)=\vec{u}^{(k)}(\theta)-\vec{u}_{\text {ens }}(\theta)
$$

The development of the ensemble averaged flow field for selected crank angles during compression is shown in Figure 14. Initially, until approximately $30^{\circ}$ CA before TDC, the flow enters the chamber from bottom left towards top right and creates a counter-clock rotating vortex on the left side. The flow in this compression phase is dominated by the tumble motion in the engine cylinder (due to the location of the two intake valves near the cylinder wall on one side). Since the tumble is aligned with the neck orientation (cf. Figures 5 and 6), it endures the passage into the combustion chamber. 


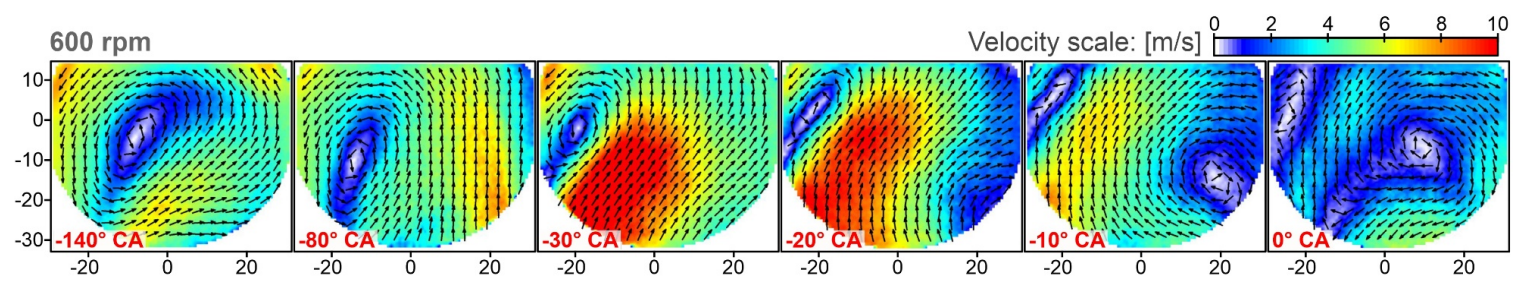

Figure 14. Ensemble averaged mean velocities (color: magnitude; arrows: flow direction) at selected crank angles in the compression stroke for the standard settings (600 rpm and peak compression pressure 100 bar).

Towards the end of the compression stroke, however, the flow entering the chamber alters its direction (now from bottom right to top left), and another (clockwise rotating) vortex forms itself at the right side. This is likely due to the slightly eccentric position of the combustion chamber/neck relative to the engine cylinder (cf. Figure 5): the squish-flow from the larger volume of the right side is stronger. The initially formed, counter-clock rotating vortex is pushed into the top left corner.

At TDC, both vortices are still present (at an engine speed of $600 \mathrm{rpm}$ ), but the velocity magnitude in the top/central area of the chamber has fallen to $3 \mathrm{~m} / \mathrm{s}$ or less.

It was found that a variation of the peak compression pressure has no significant influence on the flow field. A change of engine speed, however, has a strong effect as expected. Figure 15 shows the ensemble averaged flow fields for three engine speeds (400/600/800 rpm) at $40^{\circ}$ CA before TDC (Figure 15a) and at TDC itself (Figure 15b). At the lowest engine speed (400 rpm), the counter-clock rotating vortex formed early in the compression stroke dissipates before TDC; the velocity field in the central and upper part of the chamber is almost uniform with velocity magnitudes in the order of 1.5 $\mathrm{m} / \mathrm{s}$. The two cases with higher engine speeds (600 and $800 \mathrm{rpm}$ ) show comparable flow structures both at $40^{\circ} \mathrm{CA}$ before TDC (Figure 15a) and at TDC itself (Figure 15b); they differ mainly in the location of the vortex centers and the velocity magnitudes.
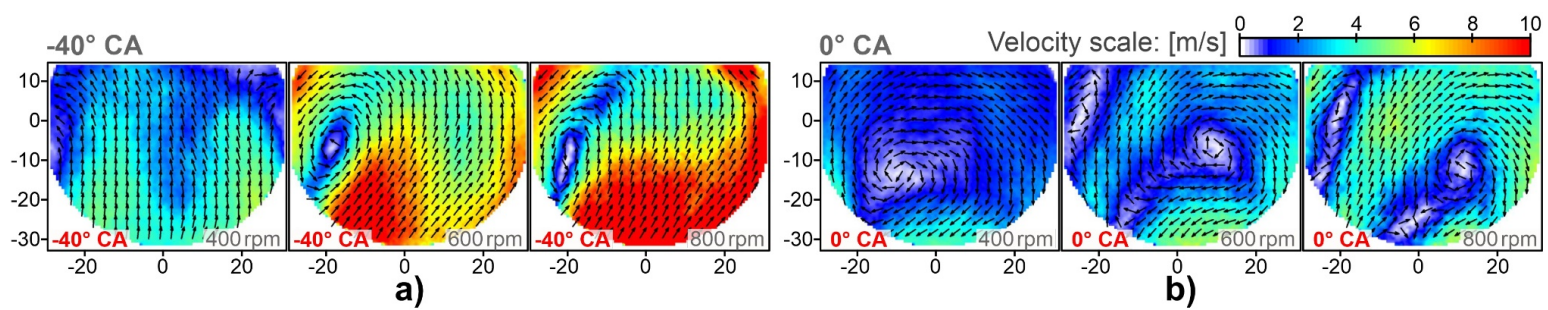

Figure 15. Ensemble averaged mean velocities (color: magnitude, arrows: flow direction) at $40^{\circ}$ CA before TDC (a) and at TDC itself (b) for a variation of engine speeds (400/600/800 rpm). Peak compression pressure 100 bar in all cases.

This means that it is possible to select the desired flow structure in the area of interest by adjusting engine speed and experiment timing (injection and ignition timing). Since the actual cylinder pressure has little influence on the flow field, the desired pressure and temperature at the time of the experiment can be adjusted separately by regulating the intake air pressure (boost pressure) and temperature (charge air preheating).

An overview of the spatially averaged flow velocity and turbulence intensity around TDC for the standard measurement settings is shown in Figure 16. All velocity values have been normalized with the mean piston speed $c_{m}(3 \mathrm{~m} / \mathrm{s}$ at $600 \mathrm{rpm})$. On the left side (Figure 16a), the mean values for the two turbulence intensity components are shown together with the gas pressure and temperature traces. The arrows beside the trace labels indicate the flexibility of the Flex-OeCoS to vary the desired operating conditions in terms of pressure, temperature and flow/turbulence conditions, as mentioned above. 


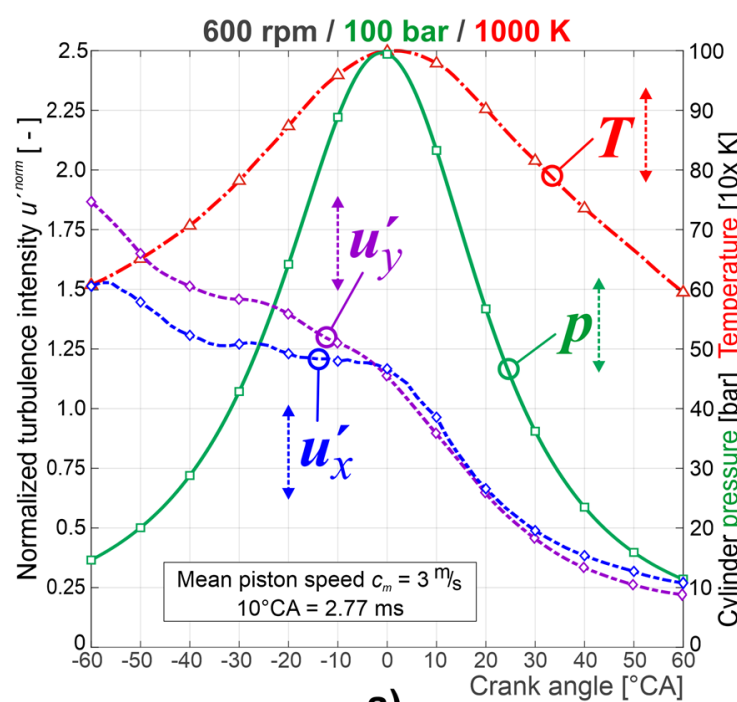

a)

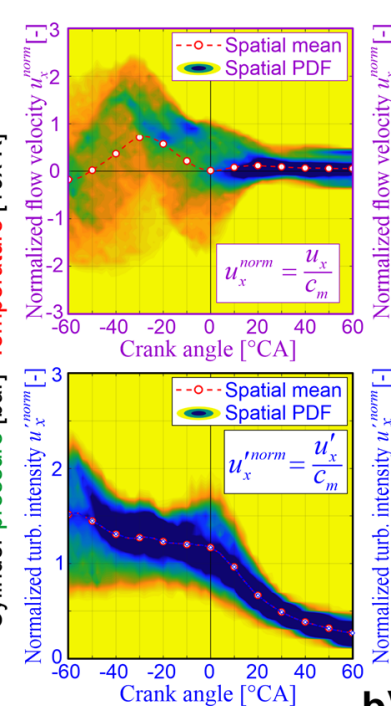

b)
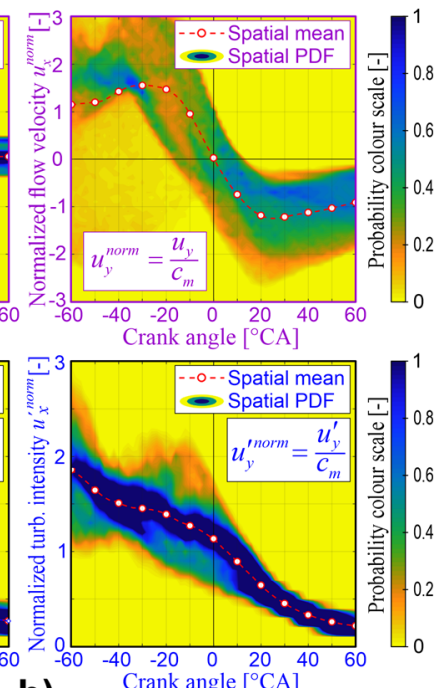

Figure 16. Normalized, spatially averaged flow velocity magnitude and ensemble averaged turbulence intensity for the standard case in the late compression/early expansion stroke without combustion. (a) Overall quantities including combustion chamber pressure and temperature trace; The arrows beside the labels indicate the flexibility of the Flex-OeCoS to vary operating parameters individually. (b) (top) The normalized spatial mean velocities in $\mathrm{x}$ and $\mathrm{y}$ direction including spatial probability density functions; (bottom) the corresponding quantities for the turbulence intensities.

On the right side (Figure 16b), the flow velocities $u_{x}$ and $u_{y}$ (top) and the turbulence intensities $u_{x}^{\prime}$ and $u_{y}^{\prime}$ (bottom) are shown. The colored background in the plots shows how often a certain flow velocity $u_{x} / u_{y}$ or turbulence intensity $u_{x}^{\prime} / u_{y}^{\prime}$ has been measured at each crank angle in the recorded experiment cycles (yellow $=$ never; dark blue $=$ very often).

As shown in Figure 13, the horizontal $x$ component is aligned perpendicular to the piston/cylinder axis, and the vertical y component is aligned parallel to the cylinder axis. During the compression stroke, the spatial probability density function of the horizontal velocity component $u_{x}$ shows quite a large variability of the mean values due to the variable entrance time of large flow structures into the combustion chamber. After TDC, no new sources for horizontal velocity components enter the chamber; the already present turbulent structures quickly break up. Therefore, the horizontal velocity $u_{x}$ drops towards zero as well. The direction of the vertical velocity component $u_{y}$ (aligned with the piston axis) represents the general movement of the gas charge in the combustion chamber due to the piston motion (note the positive values of $u_{y}$ before TDC and negative values afterwards).

The two turbulence intensity components $u_{x}^{\prime}$ and $u_{y}^{\prime}$ shown below the velocities exhibit comparable characteristics. The turbulence level falls quickly after TDC due to the decaying turbulence already present in the chamber, and due to the loss of new turbulence sources brought in with the inflow and produced by the inflow into the combustion chamber.

The turbulence intensity $u^{\prime}$ as shown in Figure 16 encompasses all variable velocity components including cyclic variations and the influence of large flow structures. Often, however, it would be important to be able to separate the overall turbulent kinetic energy into the contributions brought in from the different flow scales. To achieve this, the Proper Orthogonal Decomposition Method (POD) was applied to the measurements. This processing technique decomposes the measured flow fields into a set of empirical eigenfields $\phi_{m}(\theta)(\theta=$ Crank angle), each of which is weighted with a factor $c_{m}^{(k)}(\theta)$ that represents a fraction of the overall total kinetic energy present:

$$
\vec{u}^{(k)}(\theta)=\sum_{m=1}^{M} c_{m}^{(k)}(\theta) \cdot \phi_{m}(\theta)(M=\text { Number of measurements })
$$


The eigenfields $\phi_{m}$ are sorted with decreasing energy content (factor $c_{m}^{(k)}$ ), thus, by selecting the appropriate cut-offs it is possible to separate the most energy rich dominant structures from the coherent structures and the smallest scale, least energy containing real turbulent structures [32]:

$$
\vec{u}^{(k)}(\theta)=\vec{u}_{\text {dominant }}^{(k)}(\theta)+\Delta \vec{u}_{\text {coherent }}^{(k)}(\theta)+\Delta \vec{u}_{\text {turbulent }}^{(k)}(\theta)
$$

The definition of the used cut-offs between the structures is based on [33,34]. After the decomposition, any velocity vector field can be approximated by the superposition of the included eigenfields: To get the small-scale turbulent velocity field, for example, the weighted superposition of the dominant and coherent eigenfields are subtracted from the overall mean velocity field at this crank angle $\theta$.

Figure 17 shows some exemplary velocity fields from single modes on the right side. On the left side, the development of the turbulent kinetic energy during the compression and early expansion stroke is shown. Please note that the turbulent kinetic energy shown here is calculated from the two measured dimensions; the contribution of the unknown third dimension $u_{z}^{\prime}$ is assumed to be similar to the two measured components $\left(u_{z}^{\prime}=0.5 \cdot\left(u^{\prime}{ }_{x}+u^{\prime} y\right)\right)$.

As expected, the turbulent kinetic energy contained in the flow is much lower if the dominant or both dominant and coherent flow structures have been removed. The trends of the three turbulent kinetic energy curves however are the same (constant cut-off values).
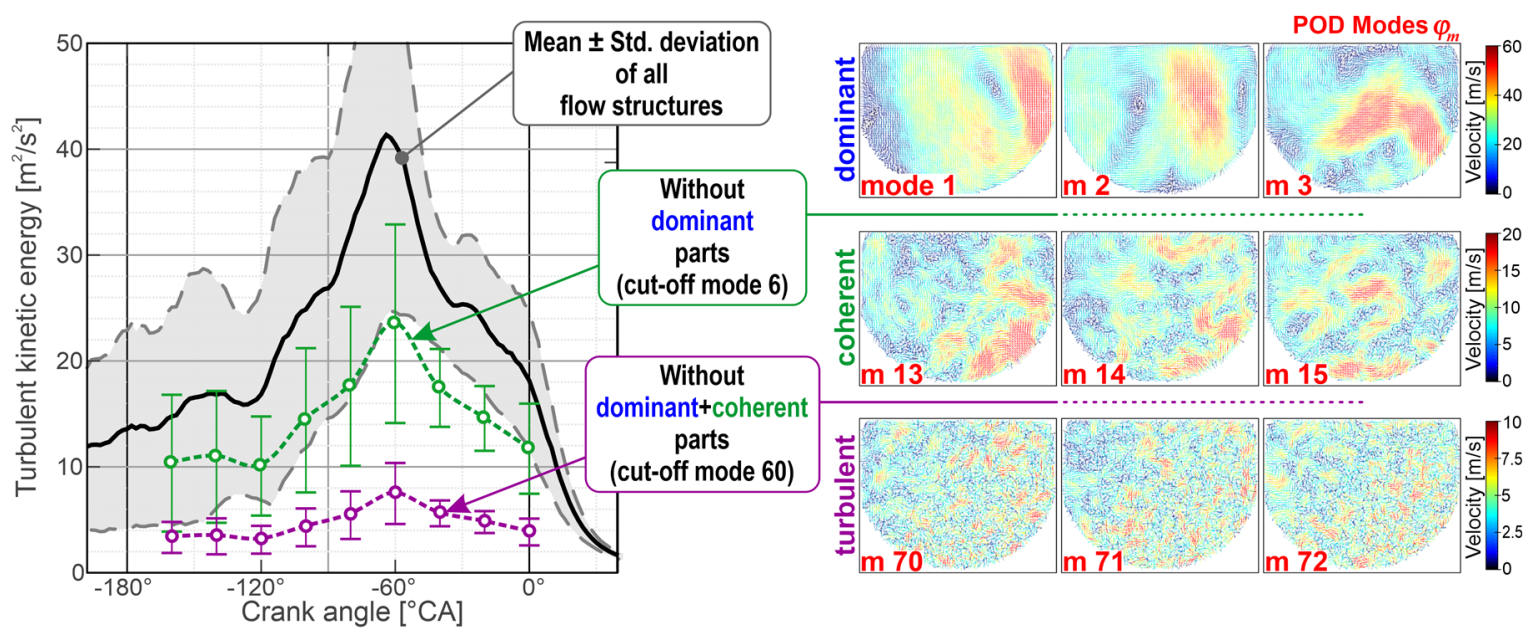

Figure 17. Crank angle dependent turbulent kinetic energy in the combustion chamber of the Flex-OeCoS for the standard measurement conditions ( $600 \mathrm{rpm} / 100$ bar). Shown are the overall values that contain all flow structures and the reduced values after the subtraction of the dominant structures or the dominant and coherent flow structures. The modes have been calculated with the Proper Orthogonal Decomposition Method (POD).

An overall assessment of the flow field measurement in the Flex-OeCoS shows that

- Flow velocity and turbulence intensity magnitude scale with engine speed.

- The pressure level has little influence on the flow structure and flow velocity or turbulence intensity magnitude.

Due to the special arrangement of combustion chamber and engine cylinder, the turbulence intensity level in the Flex-OeCoS is relatively high compared to conditions found in "normal" combustion engines. At the end of the compression stroke for standard measurement conditions ( $600 \mathrm{rpm}, c_{m}=3 \mathrm{~m} / \mathrm{s}, 100$ bar peak compression pressure), the turbulence intensities $u_{x}^{\prime}$ and $u_{y}^{\prime}$ are both in the order of $3.4 \mathrm{~m} / \mathrm{s}$ (i.e., about 1.1-1.2 times the mean piston speed $c_{m}$ ). This puts the Flex-OeCoS at 
the upper end of the range given in a collection of measurements presented in [35] (Figures 8-12, page 363).

\section{Outlook}

The optically accessible combustion chamber of the Flex-OeCoS test facility allows the application of various optical (high-speed) techniques in combination with corresponding time resolved pressure and temperature measurements as well as acquisition of further boundary conditions. Initially, the acquisition of the turbulent flow field (velocities, turbulent intensities and turbulent kinetic energy) has been performed by means of high-speed PIV.

Currently, simultaneous high-speed Schlieren/ $/ \mathrm{OH}^{*}$ chemiluminescence imaging is applied to determinate ignition properties (delay and location), flame propagation and combustion characteristics. In particular, ignition delay and combustion stability (cyclic variability) in terms of air-fuel ratio as well as start and duration of injection is under investigation.

Figure 18 gives an insight, illustrating the experimental setup at the Flex-OeCoS by means of simultaneously applied Schlieren/ $/ \mathrm{OH}^{*}$ chemiluminescence (Figure 18a) along with some exemplary images of a recording sequence (Figure 18b, Schlieren images in black and white, $\mathrm{OH}^{*}$ chemiluminescence intensity in magenta).

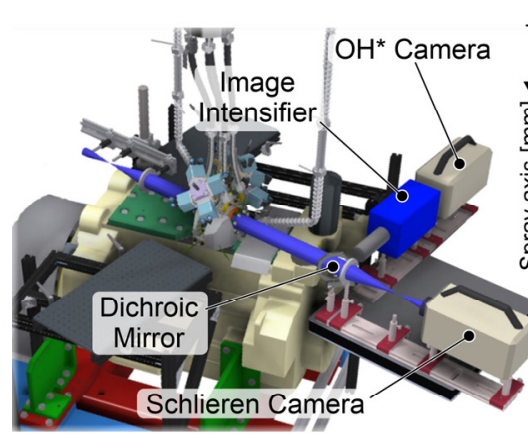

a)

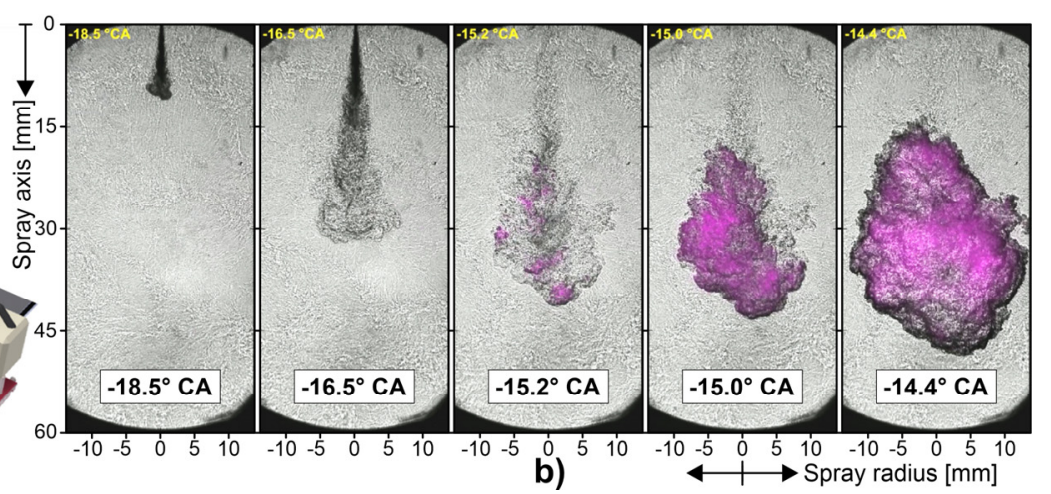

Figure 18. Optical setup at the Flex OeCoS for dual-fuel investigations by means of simultaneous Schlieren/OH* $\mathrm{OH}^{*}$ chiluminescence (a); and an exemplary high-speed recording sequence of overlaid Schlieren and (colorized) $\mathrm{OH}^{*}$ chemiluminescence (b). Operating conditions: methane/air charge $\lambda=2$, engine speed $600 \mathrm{rpm}$, pressure/temperature conditions of $70 \mathrm{bar} / 760 \mathrm{~K}$ at (hydraulic) start of injection of $-20^{\circ} \mathrm{CA}$ (dodecane pilot fuel, single hole nozzle $\varnothing 90 \mu \mathrm{m}, \mathrm{p}_{\mathrm{inj}}=1000 \mathrm{bar}$ ) with an energizing time of $525 \mu \mathrm{s}$.

The two high-speed measurement images ( $36 \mathrm{kHz}$ recording speed and $0.1^{\circ} \mathrm{CA}$ resolution) have been overlaid (and for $\mathrm{OH}^{*}$ colorized) to identify liquid pilot spray evaporation (Schlieren), the (auto) ignition process $\left(\mathrm{OH}^{*}\right.$ as tracer of initial high temperature reactivity), combustion transition (auto-ignition to premixed flame) and the subsequent propagation of the turbulent premixed flame (Schlieren).

A post-processing procedure determines start of injection, ignition delay, start of injection and start of combustion based on the optical measurements in combination with corresponding heat release analysis. Detailed results for a wide range of operating conditions will be published.

\section{Conclusions}

Thus far, optically accessible experimental test rigs for fundamental investigations are often limited in terms of operation conditions related to real engines, in particular concerning peak pressure levels. To investigate in-cylinder phenomena of modern combustion processes and fuel types (e.g., gas/dual fuel) close to engine relevant conditions, the "optical engine" facility "Flex-OeCoS" was 
developed-the designation indicating its Flexibility regarding Optical engine Combustion diagnostics and/or development of corresponding Sensing devices.

The experimental facility consists of an optical combustion chamber connected to one cylinder of a motored heavy-duty engine block. Intake air or air/(gaseous) fuel mixture (at initial conditions of up to 7 bar and $>200^{\circ} \mathrm{C}$ ) is fed through two inlet valves of the working cylinder and afterwards compressed into the combustion chamber. The timing of the two inlet and exhaust valves can be adjusted independently of the crankshaft position, allowing full flexibility of engine operation. Moreover, the drive train offers complete engine speed flexibility, adjusting the process gas charge flow velocity and turbulence conditions. The combustion chamber head offers optical accessibility with sapphire windows located at each margin, providing excellent optical access. The rectangular side windows allow application of optical light-sheet techniques, whereas the round main windows offer complete view ("see through") of the entire combustion chamber.

Comprehensive instrumentation of the combustion chamber determines in-cylinder pressure, process gas temperature and other necessary boundary conditions. In addition, the setup offers enormous flexibility to adapt individually designed plug-in inserts as replacement of the windows. Therefore, it is possible to mount specific instrumentation such as fast thermocouples, pressure sensors for calibration or even heat flux sensors. Important operating parameters and limitations such as peak pressure, characteristics of the valve train and achievable gas temperatures have been examined. A comprehensive set of precise boundary and process conditions has been determined.

The Flex-OeCoS test facility features adaptable operation at engine relevant conditions: compression and combustion pressure (up to 160 bar, respectively 230 bar), working gas temperature ( 700 to $>1000 \mathrm{~K}$ ), tunable flow/turbulence (turbulence intensity within 2-6 m/s depending on motor speed of typically $400-1000 \mathrm{rpm}$ ), adjustable gas/air charge composition and high procedure variance by pneumatic driven valve train.

Moreover, the specific design is widely adaptable by different designs of optical combustion chambers enabling investigations of distinct combustion concepts. In terms of dual fuel combustion processes, this is related to both low-pressure premixed gas/air pilot or (prechamber) flame jet ignited and high-pressure direct gas injection pilot ignited. The variability of the Flex-OeCoS test facility and its flexible operation modes offer advantageous features for various combustion research investigations.

Author Contributions: Conceptualization, B.S., K.B., and C.G.; Funding acquisition, K.B. and C.G.; Investigation, C.S., S.H., M.H., D.H., and S.W.; Supervision, K.B., C.G., and K.H.; Writing-original draft, B.S., S.H., D.H., S.W., and K.H.; and Writing-review and editing, B.S. and K.H. All authors have read and agree to the published version of the manuscript.

Funding: The development and realization of the new test rig was funded by the CCEM (Competence Center Energy and Mobility) Project "Flex-Fi-Dual" (901) and the SFOE (Swiss Federal Office of Energy) Projects "Dual Fuel Verbrennungssysteme" (SI/500970-01) and "next ICE" (SI/501020-01). Moreover, the authors gratefully thank FHNW School of Engineering as well as LAV ETH Zurich for complementary financial support.

Acknowledgments: We would like to thank Liebherr SA, Bulle, Switzerland, for contributing the base engine block for the new test rig.

Conflicts of Interest: The authors declared no potential conflicts of interest with respect to the research, authorship, and/or publication of this article.

\section{References}

1. Wei, L.; Geng, P. A review on natural gas/diesel dual fuel combustion, emissions and performance. Fuel Process. Technol. 2016, 142, 264-278. [CrossRef]

2. Costa, M.; Piazzullo, D. Biofuel powering of internal combustion engines: Production routes, effect on performance and CFD modeling of combustion. Front. Mech. Eng. 2018, 4, 9. [CrossRef]

3. Cernat, A.; Pana, C.; Negurescu, N.; Lazaroiu, G.; Nutu, C.; Fuiorescu, D.; Toma, M.; Nicolici, A. Combustion of preheated raw animal fats-diesel fuel blends at diesel engine. J. Therm. Anal. Calorim. 2019, 1-7. [CrossRef]

4. Reitz, R.D.; Duraisamy, G. Review of high efficiency and clean reactivity controlled compression ignition (RCCI) combustion in internal combustion engines. Prog. Energy Combust. Sci. 2015, 46, 12-71. [CrossRef] 
5. CCEM: CCEM Home. Available online: http://www.ccem.ch/index.html (accessed on 10 December 2019).

6. Schneider, B.M. Experimentelle Untersuchungen zur Spraystruktur in transienten, verdampfenden und nicht verdampfenden Brennstoffstrahlen unter Hochdruck. Ph.D. Thesis, ETH Zürich, Zürich, Switzerland, 2003.

7. Margari, O.-N. Optical Investigation of Soot Evolution in Spray Combustion Influence of Fuel Composition and Injection Parameters. Ph.D. Thesis, ETH Zürich, Zürich, Switzerland, 2007.

8. Wright, Y.M.; Margari, O.-N.; Boulouchos, K.; De Paola, G.; Mastorakos, E. Experiments and simulations of n-Heptane spray auto-ignition in a closed combustion chamber at diesel engine conditions. Flow. Turbul. Combust. 2010, 84, 49-78. [CrossRef]

9. Schmid, A.; Schneider, B.; Boulouchos, K.; Mojtabi, M.; Wigley, G. Experimental investigation on the spray behaviour for a hollow cone piezo injector with a multiple injection strategy. In Proceedings of the 23rd Annual Conference on Liquid Atomization and Spray Systems, Brno, Czech Republic, 6 September 2010; pp. 1-9.

10. Herrmann, K.; Schulz, R.; Weisser, G. Development of a reference experiment for large diesel engine combustion system optimization. In Proceedings of the CIMAC Congress 2007, Vienna, Austria, 21-24 May 2007; p. 15.

11. Von Rotz, B.; Herrmann, K.; Weisser, G.; Cattin, M.; Bolla, M.; Boulouchos, K.; Box, P.O.; Zürich, C. Impact of evaporation, swirl and fuel quality on the characteristics of sprays typical of large 2-stroke marine diesel engine combustion systems. In Proceedings of the ILASS-Europe 2011, 24th European Conference on Liquid Atomization and Spray Systems, Estoril, Portugal, 5-7 September 2011; pp. 1-8.

12. Von Rotz, B.; Herrmann, K.; Boulouchos, K. Experimental Investigation on the Characteristics of Sprays Representative for Large 2-Stroke Marine Diesel Engine Combustion Systems; SAE Technic Paper; SAE International: Warrendale, PA, USA, 2015. [CrossRef]

13. Schmid, A.; Yamada, N. Spray Combustion Chamber: History and Future of a Unique Test Facility. In Proceedings of the ILASS-Europe 2017. 28th Conference on Liquid Atomization and Spray Systems, Valencia, Spain, 6-8 September 2017; Universitat Politècnica València: Valencia, Spain, 2017.

14. Vera-Tudela, W.; Kyrtatos, P.; Schneider, B.; Boulouchos, K.; Willmann, M. An experimental study on the effects of needle dynamics on the penetration of a high-pressure methane jet. Fuel 2019, 253, 79-89. [CrossRef]

15. Brückner, C.; Kyrtatos, P.; Boulouchos, K. Extending the $\mathrm{NO} x$ reduction potential with miller valve timing using pilot fuel injection on a heavy-duty diesel engine. SAE Int. J. Engines 2014, 7, 1838-1850. [CrossRef]

16. Kyrtatos, P.; Zivolic, A.; Brückner, C.; Boulouchos, K. Cycle-to-cycle variations of NO emissions in diesel engines under long ignition delay conditions. Combust. Flame 2017, 178, 82-96. [CrossRef]

17. Parravicini, M.; Barro, C.; Boulouchos, K. Compensation for the differences in LHV of diesel-OME blends by using injector nozzles with different number of holes: Emissions and combustion. Fuel 2020, 259, 116166. [CrossRef]

18. Dimopoulos, P. Experimentelle Untersuchung des Strömungsfeldes in motorischen Brennräumen. Ph.D. Thesis, ETH Zürich, Zürich, Switzerland, 1996.

19. Mitakos, D.; Blomberg, C.; Vandersickel, A.; Wright, Y.; Schneider, B.; Boulouchos, K. Ignition delays of different homogeneous fuel-air mixtures in a rapid compression expansion machine and comparison with a 3-stage-ignition model parameterized on shock tube data. SAE Int. J. Engines 2013, 6, 1934-1952. [CrossRef]

20. Mitakos, D.A.; Blomberg, C.; Wright, Y.M.; Obrecht, P.; Schneider, B.; Boulouchos, K. Integration of a Cool-Flame Heat Release Rate Model into a 3-Stage Ignition Model for HCCI Applications and Different Fuels; SAE Technical. Paper Series; SAE International: Warrendale, PA, USA, 2014. [CrossRef]

21. Kammermann, T.; Giannakopoulos, G.K.; Koch, J.; Soltic, P.; Boulouchos, K. Early flame propagation of hydrogen enriched methane-air mixtures at quasi laminar conditions in a rapid compression expansion machine. Int. J. Hydrogen Energy 2019, 44, 27107-27122. [CrossRef]

22. Schlatter, S.; Schneider, B.; Wright, Y.M.; Boulouchos, K. N-heptane micro pilot assisted methane combustion in a rapid compression expansion machine. Fuel 2016, 179, 339-352. [CrossRef]

23. Srna, A. Experimental Characterization of Pilot-Fuel Ignition, Combustion, and Soot Formation in Dual-Fuel Combustion Systems. Ph.D. Thesis, ETH Zürich, Zürich, Switzerland, 2018.

24. Kammermann, T.; Koch, J.; Wright, Y.M.; Soltic, P.; Boulouchos, K. Generation of turbulence in a RCEM towards engine relevant conditions for premixed combustion based on CFD and PIV investigations. SAE Int. J. Engines 2017, 10, 2176-2190. [CrossRef] 
25. Kammermann, T. Optical Diagnostics of Ignition and Early Flame Kernel Formation in Premixed Hydrogen-Enriched Methane-Air Flames. Ph.D. Thesis, ETH Zurich, Zürich, Switzerland, 2019.

26. da Silva, M.J.; de Oliveira, A.; Sodré, J.R. Analysis of processing methods for combustion pressure measurement in a diesel engine. J. Braz. Soc. Mech. Sci. Eng. 2019, 41, 282. [CrossRef]

27. Humair, D. Acquisition of the Dynamic Gas Temperature in a Test Rig for the Examination of Combustion Processes. P8 Thesis, University of Applied Science Northwestern Switzerland, Windisch, Switzerland, 2018.

28. Kar, K.; Swain, A.K.; Raine, R. Identification of time-varying time constants of thermocouple sensors and its application to temperature measurement. J. Dyn. Syst. Meas. Control 2009, 131. [CrossRef]

29. Tagawa, M.; Shimoji, T.; Ohta, Y. A two-thermocouple probe technique for estimating thermocouple time constants in flows with combustion: In situ parameter identification of a first-order lag system. Rev. Sci. Instrum. 1998, 69, 3370-3378. [CrossRef]

30. Bargende, M. Ein Gleichungsansatz zur Berechnung der instationären Wandwärmeverluste im Hochdruckteil von Ottomotoren. Ph.D. Thesis, Technische Hochschule Darmstadt, Darmstadt, Germany, 1990.

31. Herzig, S. Erfassung des Strömungsfeldes eines Versuchsträgers zur Untersuchung von Brennverfahren mit Hilfe des berührungslosen optischen Messverfahren PIV. Master's Thesis, University of Applied Sciences and Arts Northwestern Switzerland, Windisch, Switzerland, 2018.

32. Sirovich, L. Turbulence and the Dynamics of Coherent Structures Part I: Coherent Structures. Q. Appl. Math. 1987, 45, 561-571. [CrossRef]

33. Vu, T.-T.; Guibert, P. Proper orthogonal decomposition analysis for cycle-to-cycle variations of engine flow. Effect of a control device in an inlet pipe. Exp. Fluids 2012, 52, 1519-1532. [CrossRef]

34. Bailly, C.; Comte-Bellot, G. Turbulence; Experimental Fluid Mechanics; Springer International Publishing: Cham, Switzerland, 2015; ISBN 978-3-319-16159-4.

35. Heywood, J.B. Internal Combustion Engine Fundamentals, 2nd ed.; McGraw-Hill Education: New York, NY, USA, 2018; ISBN 9781260116106.

(C) 2020 by the authors. Licensee MDPI, Basel, Switzerland. This article is an open access article distributed under the terms and conditions of the Creative Commons Attribution (CC BY) license (http://creativecommons.org/licenses/by/4.0/). 